OPEN ACCESS

Edited by:

Hua Jiang,

Leibniz Institute of Plant Genetics and Crop Plant Research (IPK),

Germany

Reviewed by:

Zhong-Hui Zhang,

South China Normal University, China Igor Kovalchuk,

University of Lethbridge, Canada

${ }^{*}$ Correspondence:

Junzhong Liu

liujunzhong@ynu.edu.cn

Zuhua $\mathrm{He}$

zhhe@cemps.ac.cn

Specialty section: This article was submitted to

Plant Cell Biology,

a section of the journal

Frontiers in Plant Science

Received: 17 August 2020 Accepted: 18 November 2020 Published: 10 December 2020

Citation:

Liu J and He Z (2020) Small DNA Methylation, Big Player in Plant Abiotic

Stress Responses and Memory.

Front. Plant Sci. 11:595603.

doi: 10.3389/fpls.2020.595603

\section{Small DNA Methylation, Big Player in Plant Abiotic Stress Responses and Memory}

\author{
Junzhong Liu' ${ }^{1 *}$ and Zuhua $\mathrm{He}^{2 *}$ \\ ${ }^{1}$ State Key Laboratory of Conservation and Utilization of Bio-Resources in Yunnan and Center for Life Sciences, School \\ of Life Sciences, Yunnan University, Kunming, China, ${ }^{2}$ National Key Laboratory of Plant Molecular Genetics, CAS Center \\ for Excellence in Molecular Plant Sciences, Shanghai Institute of Plant Physiology and Ecology, Chinese Academy \\ of Sciences, Shanghai, China
}

DNA methylation is a conserved epigenetic mark that plays important roles in maintaining genome stability and regulating gene expression. As sessile organisms, plants have evolved sophisticated regulatory systems to endure or respond to diverse adverse abiotic environmental challenges, i.e., abiotic stresses, such as extreme temperatures (cold and heat), drought and salinity. Plant stress responses are often accompanied by changes in chromatin modifications at diverse responsive loci, such as 5 -methylcytosine $(5 \mathrm{mC})$ and $N^{6}$-methyladenine $(6 \mathrm{~mA})$ DNA methylation. Some abiotic stress responses are memorized for several hours or days through mitotic cell divisions and quickly reset to baseline levels after normal conditions are restored, which is referred to as somatic memory. In some cases, stress-induced chromatin marks are meiotically heritable and can impart the memory of stress exposure from parent plants to at least the next stress-free offspring generation through the mechanisms of transgenerational epigenetic inheritance, which may offer the descendants the potential to be adaptive for better fitness. In this review, we briefly summarize recent achievements regarding the establishment, maintenance and reset of DNA methylation, and highlight the diverse roles of DNA methylation in plant responses to abiotic stresses. Further, we discuss the potential role of DNA methylation in abiotic stress-induced somatic memory and transgenerational inheritance. Future research directions are proposed to develop stress-tolerant engineered crops to reduce the negative effects of abiotic stresses.

Keywords: cytosine methylation, $N^{6}$-methyladenine DNA methylation, abiotic stress responses, somatic memory, transgenerational inheritance

\section{GLOSSARY}

Epigenetics:

The study of relatively stable and inheritable changes in gene expression caused by mechanisms independent of permanent changes in the underlying DNA sequence.

5-methylcytosine $(5 \mathrm{mC})$ methylation:

The addition of a methyl group $\left(\mathrm{CH}_{3}\right)$ to the fifth position of the pyrimidine ring of cytosine bases of DNA. 
$N^{6}$-methyladenine (6mA) DNA methylation:

The addition of a methyl group $\left(\mathrm{CH}_{3}\right)$ to the sixth position of the purine ring of adenine bases of DNA.

RNA-directed DNA methylation (RdDM):

The de novo cytosine methylation that involves small interfering RNAs (siRNAs)-generating pathway, long non-coding RNAs (lncRNAs) synthesized by plant-specific RNA Polymerase $\mathrm{V}$ (Pol V), chromatin remodeling complex, de novo DNA methyltransferase DOMAINS REARRANGED METHYL ASE 2 (DRM2) and a set of DNA or RNA-binding proteins.

Transgenerational epigenetic inheritance:

The transmittance of epigenetic states and associated certain phenotype from one generation to at least the next offspring generation through meiotic cell divisions. The transgenerational epigenetic inheritance may offer the descendants the potential to be adaptive for better fitness.

Somatic memory:

The memories that are mitotically but not meiotically heritable and only last for one generation of organisms.

\section{INTRODUCTION}

DNA methylation is a conserved epigenetic modification in eukaryotes and prokaryotes (Law and Jacobsen, 2010; Beaulaurier et al., 2019). In plants, DNA methylation predominantly occurs by the addition of a methyl group to the fifth position of the pyrimidine ring of cytosine bases or the sixth position of the purine ring of adenine bases, which is referred to as 5methylcytosine [ $5 \mathrm{mC}]$ or $N^{6}$-methyladenine [6mA], respectively (Liang et al., 2018a; Zhang H. et al., 2018). The $5 \mathrm{mC}$ occurs frequently in all three sequence contexts in plants: the symmetric CG and CHG along with the asymmetric CHH contexts (where $\mathrm{H}=\mathrm{A}, \mathrm{T}$ or C) (Zhang et al., 2006). The DNA methylation levels in plants are different in various species. In Arabidopsis thaliana, whole-genome bisulfite sequencing reveals that genome-wide levels of 24\% CG, 6.7\% CHG and 1.7\% CHH contexts are methylated, which predominantly occurs on transposons and other repetitive DNA elements (Cokus et al., 2008). In rice (Oryza sativa), the genome-wide DNA methylation level is much higher than Arabidopsis with average 44.5\% CG, 24.1\% CHG, and 4.7\% $\mathrm{CHH}$ methylation in the two cultivated rice subspecies and their wild ancestors (Li et al., 2012). $5 \mathrm{mC}$ of promoter regions usually repress gene transcription, while methylation within the gene body quantitatively impedes transcript elongation in Arabidopsis (Zilberman et al., 2007). However, in some genomic regions, two SU(VAR)3-9 homologs, SUVH1, and SUVH3, serve as the methyl reader and recruit two DNAJ domain-containing homologs, DNAJ1 and DNAJ2 to increase the expression of proximal neighboring genes (Harris et al., 2018). $5 \mathrm{mC}$ plays important roles in defending the genome against selfish DNA elements and regulating gene expression, which are essential for normal plant growth, development and reproduction as well as appropriate biotic and abiotic stress responses (Zhang H. et al., 2018).

Compared with $5 \mathrm{mC}$, the $6 \mathrm{~mA}$ abundance in plants is rather lower, ranging from $0.006 \%$ to $0.138 \%$ in 9-day-old Arabidopsis wild-type Col to $0.15-0.55 \%$ in rice seedlings (Liang et al., 2018b;
Zhang Q. et al., 2018; Zhou et al., 2018). In Arabidopsis and rice, $6 \mathrm{~mA}$ occurs most frequently at plant-specific ANYGA as well as GAGG motifs which is conserved in plantae and animalia (Liang et al., 2018b; Zhang Q. et al., 2018; Zhou et al., 2018). $6 \mathrm{~mA}$ sites are widely distributed across the Arabidopsis genome and $32 \%$ of $6 \mathrm{~mA}$ sites are located within gene bodies, while in rice, $6 \mathrm{~mA}$ locates at about $20 \%$ of genes and $14 \%$ of transposable elements (Liang et al., 2018b; Zhou et al., 2018). $6 \mathrm{~mA}$ seems to be positively associated with gene expression and contributes to plant developments and stress responses (Zhang Q. et al., 2018).

During their immobile lifecycles, plants are exposed to a variety of adverse abiotic stresses, such as drought (water deficiency), salinity (salt), and temperature stresses (heat and cold). These stresses not only inhibit the growth and development of plants, but also pose great threats to crop yield and food safety. Drought and extreme heat have significantly reduced national cereal production by $9-10 \%$, according to the records from the Emergency Events Database and Food and Agriculture Organization of the United Nations during 1964-2007 (Lesk et al., 2016). From 1980 to 2008, global warming has declined the global maize (Zea mays) and wheat (Triticum aestivum) production by 3.8 and 5.5\%, respectively (Lobell et al., 2011). Like other abiotic stresses, cold stress, including chilling stress $(0-$ $15^{\circ} \mathrm{C}$ ) and freezing stress (below $0^{\circ} \mathrm{C}$ ), also threatens crop yield and quality, and causes tremendous agricultural yield penalty and economic losses worldwide (Ding et al., 2020). Salinity is another one of the most destructive environmental factors, which affects about $20 \%$ of irrigated land and threatens different traits of crop plants, such as the growth rate, photosynthesis, transpiration, yield and quality (Negrão et al., 2017).

To survive in the adverse circumstances, plants employ diverse genetic and epigenetic strategies for regulation of plant growth, development, reproduction and immunity in response to endogenous and exogenous stress signals. The abiotic stress signaling and responses in plant have been extensively studied and recently well summarized (Zhu, 2016; Gong et al., 2020). Plants have evolved quick and sophisticated sensory mechanisms to perceive the abiotic stress cues, convert them to cellular signals and transmit the signals within cells and tissues. So far, several abiotic stress sensors have been identified, such as putative salt sensor glycosyl inositol phosphorylceramide (GIPC) sphingolipids (Jiang et al., 2019), putative cold stress sensor chilling tolerance divergence 1 (COLD1) (Ma Y. et al., 2015), hyperosmotic stress sensor OSCA1 (Yuan et al., 2014), putative heat sensor phytochrome B (phyB) (Jung et al., 2016; Legris et al., 2016), cyclic nucleotide-gated $\mathrm{Ca}^{2+}$ channels (CNGCs) (Saidi et al., 2009) and histone variant H2A.Z (Kumar and Wigge, 2010). Upon the perception of abiotic stress signals, these sensors are activated by altering their structure, activity or interacting partners to initiate multilayer downstream stress responses, such as the activation of stress-responsive genes, the regulation of RNA, protein, metabolism and ROS homeostasis. Although the signaling pathways underlying plant responses to different abiotic stresses vary, there are some common theme in the key downstream signaling pathways, such as mitogenactivated protein kinase (MAPK) cascades, G-protein signaling, calcium signaling and hormone signaling (Zhu, 2016). 
Besides the significant progress in elucidating the genetic basis of plant abiotic stress responses, great achievements have been made in dissecting the complicated epigenetic regulatory mechanisms in plant adaption to the adverse environments. As one of the most important epigenetic modifications, DNA methylation plays important roles in stress responses in diverse plant species. However, the roles and mechanisms of DNA methylation in plant abiotic stress responses remain largely scattered and fragmented. In this review, we briefly summarize recent progress on the establishment, maintenance and erasing of $5 \mathrm{mC}$ and $6 \mathrm{~mA}$, and present the divergent roles of DNA methylation in plant responses to different abiotic stresses. Further, we discuss the potential role of DNA methylation in abiotic stress-induced somatic memory and transgenerational inheritance. Finally, we propose some future research directions to breed crops with enhanced stress tolerances.

\section{DNA METHYLATION}

\section{$5 \mathrm{mC}$ Methylation}

\section{Establishment of $5 \mathrm{mC}$ by the RNA-Directed DNA Methylation Pathway}

In 1994, for the first time, de novo $5 \mathrm{mC}$ methylation of genes is found to be induced and targeted by their own RNAs in transgenic tobacco plants infected with viroid (Wassenegger et al., 1994). This phenomenon is described as RNA-directed DNA methylation (RdDM). In the past 26 years, extensive studies have revealed an accumulating knowledge of RdDM. De novo $5 \mathrm{mC}$ methylation in all sequence contexts is directed by small RNAs and catalyzed by DOMAINS REARRANGED METHYLTRANSFERASE 2 (DRM2) in plants (Zhang H. et al., 2018). The DRM2 activity is regulated by the canonical and non-canonical RdDM pathways, which mainly differs in the small RNAs-generating pathway (Figure 1A; Cuerda-Gil and Slotkin, 2016). Small RNAs are 18-30 nucleotide (nt) nonprotein-coding RNAs, which mediate post-transcriptional gene silencing (PTGS) through slicing or translational inhibition, or transcriptional gene silencing (TGS) by targeting chromatin for cytosine or histone methylation. According to their biogenesis and modes of regulation, small RNAs in plants can be divided into two major types: microRNAs (miRNAs) and small interfering RNAs (siRNAs) (Borges and Martienssen, 2015). In the canonical RdDM pathway in Arabidopsis, the plantspecific RNA polymerase IV (Pol IV) transcribes heterochromatic regions to generate 30 to $40-n t$ short RNAs, which are referred to as P4 RNAs (Zhai et al., 2015). RNA-DEPENDENT RNA POLYMERASE 2 (RDR2) then converts P4 RNAs into double-stranded RNAs (dsRNAs) and typically adds an extra untemplated $3^{\prime}$ terminal nucleotide to the second strands. The dsRNAs are processed by RNase III-class endonuclease DICERLIKE 3 (DCL3) to generate 24- and 23-nt heterochromatic siRNAs (hc-siRNAs) (Singh et al., 2019). The 24-nt hc-siRNAs are exported to the cytoplasm and preferentially incorporated into ARGONAUTE 4 (AGO4) or AGO6, which are re-imported to the nucleus with the help of HEAT SHOCK PROTEIN 90 (HSP90) (Ye et al., 2012). In the nucleus, target loci (mostly transposons and repeats) are transcribed by plant-specific RNA polymerase $\mathrm{V}(\mathrm{Pol} \mathrm{V})$ to generate non-protein-coding nascent scaffold transcripts, which base-pair with the 24-nt hc-siRNAs by sequence complementarity, resulting in the DRM2 recruitment and DNA methylation at the source loci. A variety of RNA binding proteins, methylated DNA binding proteins, chromatinremodeling complex and key enzymes responsible for histone $\mathrm{H} 3$ lysine 9 dimethylation (H3K9me2) also participate in the establishment of de novo DNA methylation (Figure 1B; Zhang H. et al., 2018).

In addition to this canonical Pol IV-RDR2-DCL3-dependent RdDM pathway, several types of non-canonical RdDM pathways have been reported, including Pol II-DCL3 RdDM pathway, RDR6 RdDM pathway, RDR6-DCL3 RdDM pathway, Pol IVNEEDED FOR RDR2-INDEPENDENT DNA METHYLATION (NERD) RdDM pathway, and dicer-independent RdDM pathway (Figure 1A; Cuerda-Gil and Slotkin, 2016). Pol II transcripts of some inverted repeat (IR) sequences and miRNA precursors can also be cleaved by DCL3 to produce 24-nt small RNAs, which participate in RdDM in cis or trans (Slotkin et al., 2005; Chellappan et al., 2010; Khraiwesh et al., 2010; Wu et al., 2010). In the RDR6 RdDM pathway, Pol II transcripts of trans-acting siRNA (TAS) genes and some transcriptionally active transposable elements (TEs) are cleaved by AGO1-bound small RNA-induced silencing complex (RISC), converted into dsRNAs by RDR6, and further cleaved by DCL2/4 into 21-22nt secondary siRNAs, which are loaded onto AGO6 to initiate RdDM (Wu et al., 2012; Nuthikattu et al., 2013; McCue et al., 2015). High copy number or elevated expression of TEs such as retrotransposon Evadé (EVD) can also induce the biosynthesis of dsRNAs by RDR6, but such dsRNAs are cleaved by DCL3 to produce 24-nt siRNAs to initiate RdDM, which is referred to as the RDR6-DCL3 RdDM pathway (Marí-Ordóñez et al., 2013). As EVD is originally a target of PTGS, the RDR6-DCL3 RdDM pathway may be an important mechanism to silence active TEs when PTGS is saturated (Cuerda-Gil and Slotkin, 2016). In the Pol IV-NERD RdDM pathway, the transcripts of a subset of non-conserved genomic loci are produced by Pol IV but generate 21-nt siRNAs through the sequential roles of RDR6 and DCLs in Arabidopsis. The 21-nt siRNAs are loaded to AGO2 and initiate RdDM dependent of NERD, a GW repeat- and PHD finger-containing protein (Pontier et al., 2012). Recently, two groups have reported the dicer-independent RdDM in Arabidopsis, in which the dicer-independent siRNAs are generated by distributive $3^{\prime}-5^{\prime}$ exonucleases (Yang et al., 2015; Ye et al., 2015). In summary, these diverse non-canonical RdDM pathways feed into the canonical RdDM pathways and play subsidiary roles in RdDM pathways.

\section{Maintenance of $5 \mathrm{mC}$ in Different Contexts}

In plants, DNA methylation in three different contexts is maintained by three different pathways. CG, CHG and asymmetric $\mathrm{CHH}$ methylation are maintained by METHYLTRANSFERASE 1 (MET1), CHROMOMETHYLASE 3 (CMT3)/CMT2, DRM2/CMT2, respectively (Figure 1C; Zhang H. et al., 2018). In Arabidopsis, MET1, ortholog of mammalian DNA methyltransferase DNMT1, is required for the 


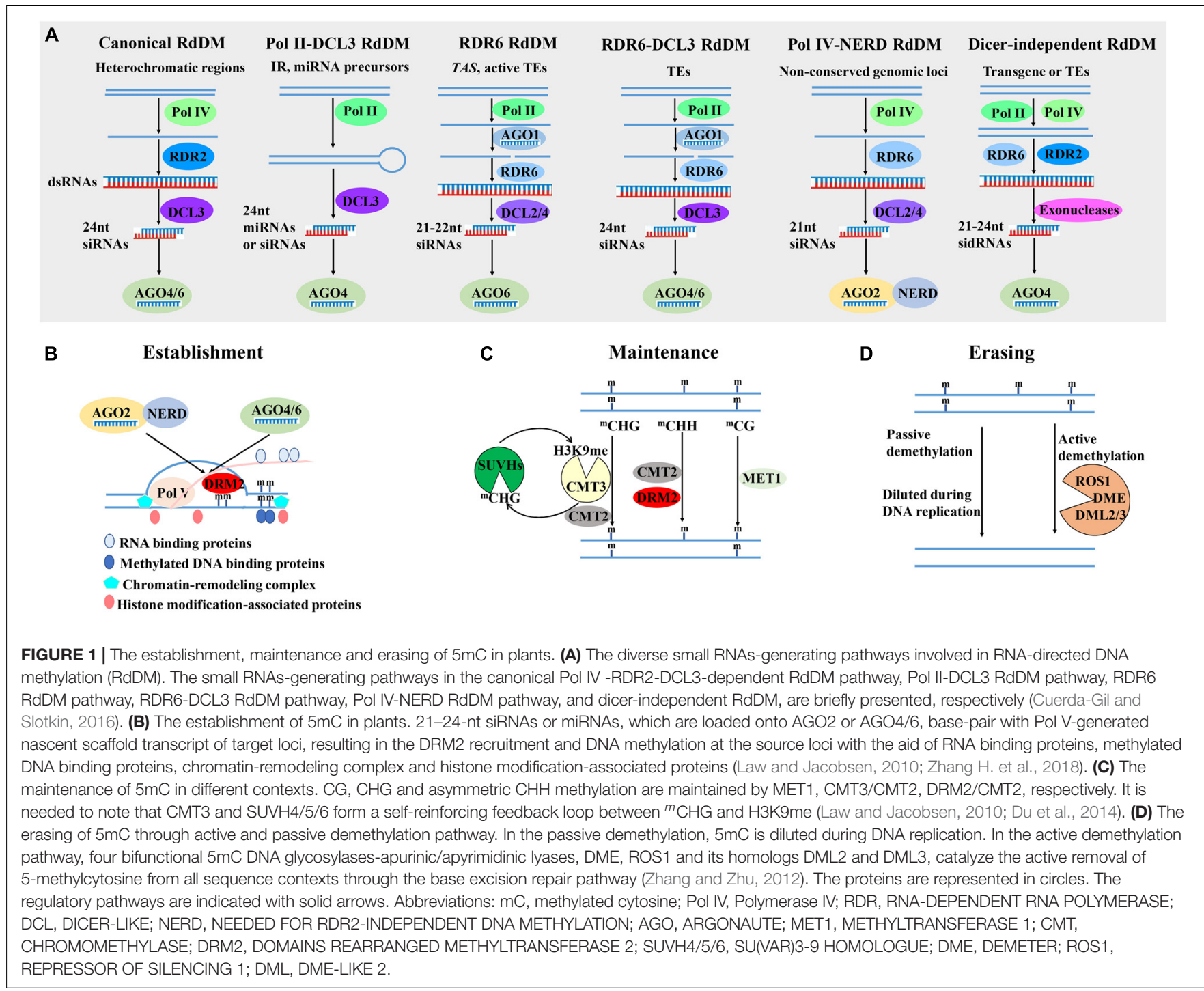

maintenance of CG methylation and normal plant development (Finnegan et al., 1996). During plant mitosis and gametogenesis, MET1 recognizes the hemi-methylated templates and induces the methylation of unmodified CG dinucleotides in the daughter strand (Saze et al., 2003; Zhang H. et al., 2018). The rice genome encodes two closely related putative MET1, OsMET1-1, and OsMET1-2, but only the loss-of-function of OsMET1-2 leads to genome-wide hypomethylation and seedling lethality ( $\mathrm{Hu}$ et al., 2014). In Arabidopsis, VARIANT IN METHYLATION 1-3 (VIM1-3), SRA (SET- and RING-associated) domain methylcytosine-binding proteins, play overlapping roles in the maintenance of global CG methylation in collaboration with MET1 (Woo et al., 2008; Kim et al., 2014).

In the genetic screens for reduced methylation of Arabidopsis SUPERMAN locus and PHOSPHORIBOSYLANTHRANILATE ISOMERASE (PAI), plant-specific methyltransferase CMT3 is found to be indispensable for the maintenance of $\mathrm{CHG}$ methylation (Bartee et al., 2001; Lindroth et al., 2001). CMT3-mediated CHG methylation depends on H3K9 histone methyltransferase KRYPTONITE/SUVH4 (KYP) (Jackson et al., 2002). CMT3 and KYP form a self-reinforcing feedback loop between ${ }^{m} \mathrm{CHG}$ and $\mathrm{H} 3 \mathrm{~K} 9 \mathrm{me}$. In the loop, CMT3 is recruited by $\mathrm{H} 3 \mathrm{~K} 9 \mathrm{me}$ and methylate $\mathrm{CHG}$ DNA to create binding sites for KYP and its close homologs SU(VAR)3-9 HOMOLOGUE 5 (SUVH5) and SUVH6; in turn, KYP can methylate H3K9 to generate the binding sites for CMT3 (Figure 1C; Law and Jacobsen, 2010; Du et al., 2014). Zea methyltransferase2 (ZMET2) in maize, ortholog of AtCMT3, is also required for ${ }^{m} \mathrm{CHG}$ (Papa et al., 2001). Crystal structure analysis of ZMET2 and H3K9me2 have revealed that ZMET2 binds $\mathrm{H} 3 \mathrm{~K} 9 \mathrm{me} 2$ via bromo adjacent homology (BAH) and chromo domains (Du et al., 2012).

$\mathrm{CHH}$ methylation is mainly maintained by the DRM2mediated de novo methylation and RdDM pathway (Figure 1C). Besides DRM2, CMT2 mediates $\mathrm{CHH}$ methylation at some long TEs through binding to H3K9 methylation (Stroud et al., 2014). Moreover, CMT2 also mediates CHG methylation. Therefore, CMT2, CMT3 and DRM2 collaborate to maintain non-CG methylation, and form self-reinforcing feedback loops 
with H3K9 methylation (Stroud et al., 2014). DECREASE IN DNA METHYLATION 1 (DDM1), a SWI2/SNF2-like chromatin remodeling enzyme, can facilitate CMT2 to access H1containing heterochromatin to maintain RdDM-independent $\mathrm{CHH}$ methylation (Zemach et al., 2013). In maize, ZmDDM1 regulates the formation of ${ }^{m} \mathrm{CHH}$ islands through the RdDM pathway (Long et al., 2019). However, in rice, OsDDM1 antagonizes RdDM at heterochromatin and represses non-coding RNA expression from repetitive sequences (Tan et al., 2018), suggesting the distinct roles of DDM1 in different species.

\section{Erasing of $5 \mathrm{mC}$ Through Active and Passive Demethylation Pathway}

In plant growth, development, reproduction and stress responses, $5 \mathrm{mC}$ is dynamically regulated by DNA methyltransferases and demethylation pathways. There are two demethylation pathways in plants: passive and active demethylation pathways (Figure 1D). The passive demethylation is a process in which $5 \mathrm{mC}$ is diluted from the genome during DNA replication, usually due to the down-regulation of DNA methyltransferase activity or shortage of the methyl donor folate (Zhang H. et al., 2018). In Arabidopsis gametogenesis, loss of MET1 in the diploid central cell and the haploid egg cell as well as the loss of DDM1 and Pol IV in the vegetative cell decrease $5 \mathrm{mC}$ and strongly reactivate transposons, resulting in the production of siRNAs that may travel to sperm cells or egg cells to reinforce TE silencing (Bourc'his and Voinnet, 2010; Feng et al., 2010).

In the active demethylation pathway, four bifunctional $5 \mathrm{mC}$ DNA glycosylases-apurinic/apyrimidinic lyases, DEMETER (DME), REPRESSOR OF SILENCING 1 (ROS1) and its homologs DME-like 2 (DML2) and DML3, have been implicated in the active removal of 5-methylcytosine from all sequence contexts through the base excision repair (BER) pathway (Zhang and Zhu, 2012; Liu and Lang, 2020). ROS1 is the first identified DNA glycosylase/lyase involved in DNA demethylation (Gong et al., 2002). The recruitment of ROS1 to its target genomic regions is mediated by INCREASED DNA METHYLATION (IDM) complex (Zhang $H$. et al., 2018). Interestingly, the expression of ROS1 is promoted by DNA methylation and a sequence in its promoter functions as a DNA methylation monitoring sequence (MEMS) that senses DNA methylation levels and regulates ROS1 expression to fine-tune genomic DNA methylation (Lei et al., 2015; Williams et al., 2015). DME is preferentially expressed in companion cells of the female and male gametes and initiates active DNA demethylation, which is required for endosperm genomic imprinting and embryo viability (Park et al., 2017).

\section{$N^{6}$-Methyladenine DNA Methylation (6mA)}

As a new epigenetic marker in eukaryotes, the establishment, maintenance and erasing of $6 \mathrm{~mA}$ remain largely obscure. In mammalian, $N^{6}-\mathrm{mA}$ is catalyzed by methyltransferase N6MT1 and removed by 2-oxoglutarate-dependent oxygenase AlkB homolog 1 (ALKBH1) (Xiao et al., 2018; Zhang M. et al., 2020). In rice, OsALKBH1 is proposed to function as $6 \mathrm{~mA}$ demethylase, as the loss function of OsALKBH1 results in increased $6 \mathrm{~mA}$ levels (Zhou et al., 2018). 6mA levels are significantly decreased in Osddm1a/ddm1b double mutants, suggesting that OsDDM1a and OsDDM1b are indispensable for $6 \mathrm{~mA}$ modification in rice (Zhang Q. et al., 2018). Recent studies have revealed that $6 \mathrm{~mA}$ DNA modification is positively correlated with gene activation and plays important roles in plant development, and stress responses (Liang et al., 2018b; Zhang Q. et al., 2018; Zhou et al., 2018). For better understanding of the roles of $6 \mathrm{~mA}$ in plants, it is urgent to identify the key writer and reader of $6 \mathrm{~mA}$ in plants.

\section{THE DIVERGENT ROLES OF DNA METHYLATION IN PLANT ABIOTIC STRESS RESPONSES}

In recent years, multiple technologies have been developed for detecting methylation levels of genome-wide DNA or specific sequence contexts, such as Chop-PCR, methylation sensitive amplification polymorphism (MSAP) technique, methylated DNA immunoprecipitation sequencing (MeDIP-Seq) or $6 \mathrm{~mA}$ IP-Seq, and whole genome bisulfite sequencing (WGBS). Using partial digestion by methylation-sensitive restriction enzymes followed by PCR amplification, Chop-PCR can detect the cytosine methylation at the cleavage sites that protects DNA against digestion and therefore can be amplified using PCR (Dasgupta and Chaudhuri, 2019). MSAP is widely applied for analysis of differentially methylated CCGG sites in different plant species with the use of isoschizomers with different methylation sensitivity (such as HpaII and MspI) (Guevara et al., 2017). For MeDIP-Seq and 6mA-IP-Seq, specific antibodies are used to isolate methylated DNA from genomic DNA via immunoprecipitation. WGBS is a sensitive and robust method for genome-wide analysis of $5 \mathrm{mC}$ at single-base resolution in plants. These techniques greatly promote the research on the roles of DNA methylation under abiotic stress conditions. The detailed roles of $5 \mathrm{mC}$ and $6 \mathrm{~mA}$ in plant heat, cold, salt and drought stress responses are reviewed as follows.

\section{Heat Stress}

Most plants can only tolerate a certain range of temperature fluctuations. The elevation in temperature, which is $10-15^{\circ} \mathrm{C}$ beyond the ambient favorable threshold, is referred to as heat stress. There are two-tiered plant tolerance to heat stress: basal and acquired thermotolerance. The basal thermotolerance is an inherent ability for plants to respond and successfully acclimate to heat stress, while acquired thermotolerance means the ability of plants to survive in lethal heat stress after acclimatization to mild heat stress (also known as priming) (Mittler et al., 2012). The thermotolerance in plants are regulated by multiple epigenetic modifications, including DNA methylation (Liu et al., 2015).

Heat stress triggers $5 \mathrm{mC}$ demethylation globally or at some loci in some plant species. In cotton (Gossypium hirsutum) anthers, heat stress ( 35 to $39^{\circ} \mathrm{C} / 29$ to $31^{\circ} \mathrm{C}$ day/night) disrupts the global DNA methylation, especially $\mathrm{CHH}$ methylation, in a heat-sensitive line, whereas a heat-tolerant line shows higher methylation level (Min et al., 2014; Ma et al., 2018). The heatinduced down-regulation of S-ADENOSYL-L-HOMOCYSTEINE 
HYDROLASE1 (SAHH1) and DNA methyltransferases DRM1/3 may contribute to the genome-wide hypomethylation under heat stress (Min et al., 2014). The reduction of DNA methylation may result in the disruption of sugar and reactive oxygen species (ROS) metabolic pathways, leading to microspore sterility (Ma et al., 2018). In soybean (Glycine max L.), heat stress $\left(40^{\circ} \mathrm{C}\right.$ for $3 \mathrm{~h}$ ) also induces the hypomethylation in all three contexts, especially the ${ }^{m} \mathrm{CHH}$, in both root hairs and stripped roots (Hossain et al., 2017). In cultured microspores of Brassica napus cv. Topas, heat shock treatment $\left(32^{\circ} \mathrm{C}\right.$ for $\left.6 \mathrm{~h}\right)$ triggers DNA hypomethylation, particularly in CG and CHG contexts (Li et al., 2016). Another research reveals that after heat stress $\left(37^{\circ} \mathrm{C}\right.$ for $2 \mathrm{~h}$, and then $45^{\circ} \mathrm{C}$ for $3 \mathrm{~h}$ ), more DNA demethylation events occur in the heat-tolerant genotype, while more DNA methylation events occur in the heat-sensitive genotype in Brassica napus (Gao et al., 2014). In rice, OsCMT3 is repressed by heat stress, which may partly lead to the upregulation of FERTILIZATION-INDEPENDENT ENDOSPERM 1 (OsFIE1), a member of Polycomb Repressive Complex 2 (PRC2). The elevated expression of OsFIE1 may regulate seed size under heat stress (Figure 2A; Folsom et al., 2014). The effect of heatinduced repression of OsCMT3 on the global $5 \mathrm{mC}$ remains to be investigated in rice.

In the model dicot Arabidopsis thaliana, the effect of heat stress on key players in 5mC, such as DNA methyltransferases, DNA demethylases, RdDM components, are distinct. These players play diverse roles in thermotolerance through modulating $5 \mathrm{mC}$ or other regulatory processes. Heat stress $\left(36^{\circ} \mathrm{C}\right.$ for $\left.48 \mathrm{~h}\right)$ induced up-regulation of DRM2, NUCLEAR RNA POLYMERASE $D$ 1A (NRPDIA) and NRPD1B, the largest subunits of PoI IV and Pol V, respectively. nrpd1a-1 nrpd1b-1 double mutation abolished DNA methylation in the promoter of Calmodulinlike 41 (CML41) and At5g43260, and suppressed their heatinduced increased expression, suggesting the important roles of $\mathrm{PoI} I V$ and $\mathrm{Pol} \mathrm{V}$ in regulating gene expression under heat stress (Figure 2B; Naydenov et al., 2015). Arabidopsis plants deficient in NRPD2, the common second-largest subunit of PoI IV and Pol V, are hypersensitive to acute heat stress $\left(42^{\circ} \mathrm{C}\right.$ for 24-34 h). Loss-of-function of RdDM components, RDR2, DCL3 and AGO4 also dramatically decrease the basal thermotolerance (Figure 2C; Popova et al., 2013). In $n r p d 2$ mutants recovered from heat stress, the misexpression of protein-coding genes, such as auxin-responsive genes, may be affected by their adjacent transposon remnants, which are induced by heat stress (Popova et al., 2013). However, cmt2 mutant plants and accessions with $C M T 2_{S T O P}$ allele display increased tolerance to heat stress $\left(37.5^{\circ} \mathrm{C}\right.$ for $\left.24 \mathrm{~h}\right)$, natural variation in $C M T 2$ and associated changes in genome-wide $\mathrm{CHH}$-methylation pattern contribute to the natural adaptation to variable temperatures (Figure 2D; Shen et al., 2014). Some new identified players involved in DNA methylation also play roles in plant heat responses. Depletion of MutS HOMOLOGUE 1 (MSH1) in Arabidopsis results in genomewide reprogramming of DNA methylation (Virdi et al., 2015). Intriguingly, crossing or grafting of the msh1 mutant to wild type or hemi-complementation of mitochondrial function in the msh1 mutant can lead to an enhancement of growth vigor and heat tolerance, which may be associated with changes in DNA methylation (Figure 2E; Virdi et al., 2015, 2016). The detailed roles of MSH1 in thermotolerance remain to be investigated. Above all, despite the divergent effects of different key players in $5 \mathrm{mC}$ on heat responses, it is no doubt that DNA methylation is important for thermotolerance in Arabidopsis.

Heat stress can release the TGS and PTGS of various transgenes and some endogenous loci in Arabidopsis, such as exogenous $\beta$-glucuronidase (GUS), 35S promoter of Cauliflower Mosaic Virus, endogenous imprinted gene SDC and several repetitive elements (transposons and retrotransposons) (LangMladek et al., 2010; Pecinka et al., 2010; Tittel-Elmer et al., 2010; Zhong et al., 2013; Cavrak et al., 2014; Sanchez and Paszkowski, 2014). However, heat-induced activation of these loci occurs without loss of $5 \mathrm{mC}$ or seems not to be associated with changes of local 5mC. A COPIA-type retrotransposon ONSEN can be activated by heat stress and its retrotransposition confers heat-responsiveness to genes close to the new insertion site. In plants deficient in siRNA-biogenesis in RdDM, the heatinduced retrotransposition of ONSEN can be transmitted to the unstressed progeny. However, the heat-induced reduction of $\mathrm{CHH}$ methylation in ONSEN promoter cannot account for the activation of ONSEN under heat stress (Ito et al., 2011; Cavrak et al., 2014).

The $6 \mathrm{~mA}$ levels are positively correlated with heat tolerance in rice (Zhang Q. et al., 2018). Heat stress up-regulates total $6 \mathrm{~mA}$ levels in both Japonica group cultivar Nipponbare (Nip) and Indica group cultivar 93-11, and the fold change of $6 \mathrm{~mA}$ level in 93-11 is 2.6-fold greater than that in Nip. In the signal transduction of heat stress, heat shock transcription factors (HSFs) and heat shock proteins (HSPs) are central players (Mittler et al., 2012). The heat-induced up-regulation of OsHSFA 1 and down-regulation of OsHSP70 positively correlated with changes in their $6 \mathrm{~mA}$ levels in 93-11, which may contribute to the more tolerance to heat stress of 93-11 compared with Nip (Figure 2F; Zhang Q. et al., 2018). Whether heat-induced up-regulation of $6 \mathrm{~mA}$ is conserved in diverse species remains to be elucidated.

In summary, DNA methylation play some noticeable roles in plant heat stress responses. However, the exact roles of DNA methylation in the sensing and signal transduction of heat stress remain unclear in plants. Further studies should pay more attention to the possible roles of DNA methylation in the perception and signaling of heat stress in plants.

\section{Cold Stress}

In plants, the cold signal can be perceived by putative cold sensors, such as the G-protein regulator COLD1 and CBLINTERACTING PROTEIN KINASE 7 (OsCIPK7) (Ma Y. et al., 2015; Zhang et al., 2019). The PM and ER-localized COLD1 interacts with the RICE G-PROTEIN $\alpha$ SUBUNIT 1 (RGA1) to activate the $\mathrm{Ca}^{2+}$ channel and accelerate the influx of extracellular $\mathrm{Ca}^{2+}$, which confers chilling tolerance in rice (Ma Y. et al., 2015). OsCIPK7 with a point mutation at the activation loop of the kinase domain exhibits enhanced kinase activity and confers chilling tolerance through $\mathrm{Ca}^{2+}$ influx in rice (Zhang et al., 2019). The cold-induced cytosolic $\mathrm{Ca}^{2+}$ signal can initiate downstream signaling pathways, such as calcium 


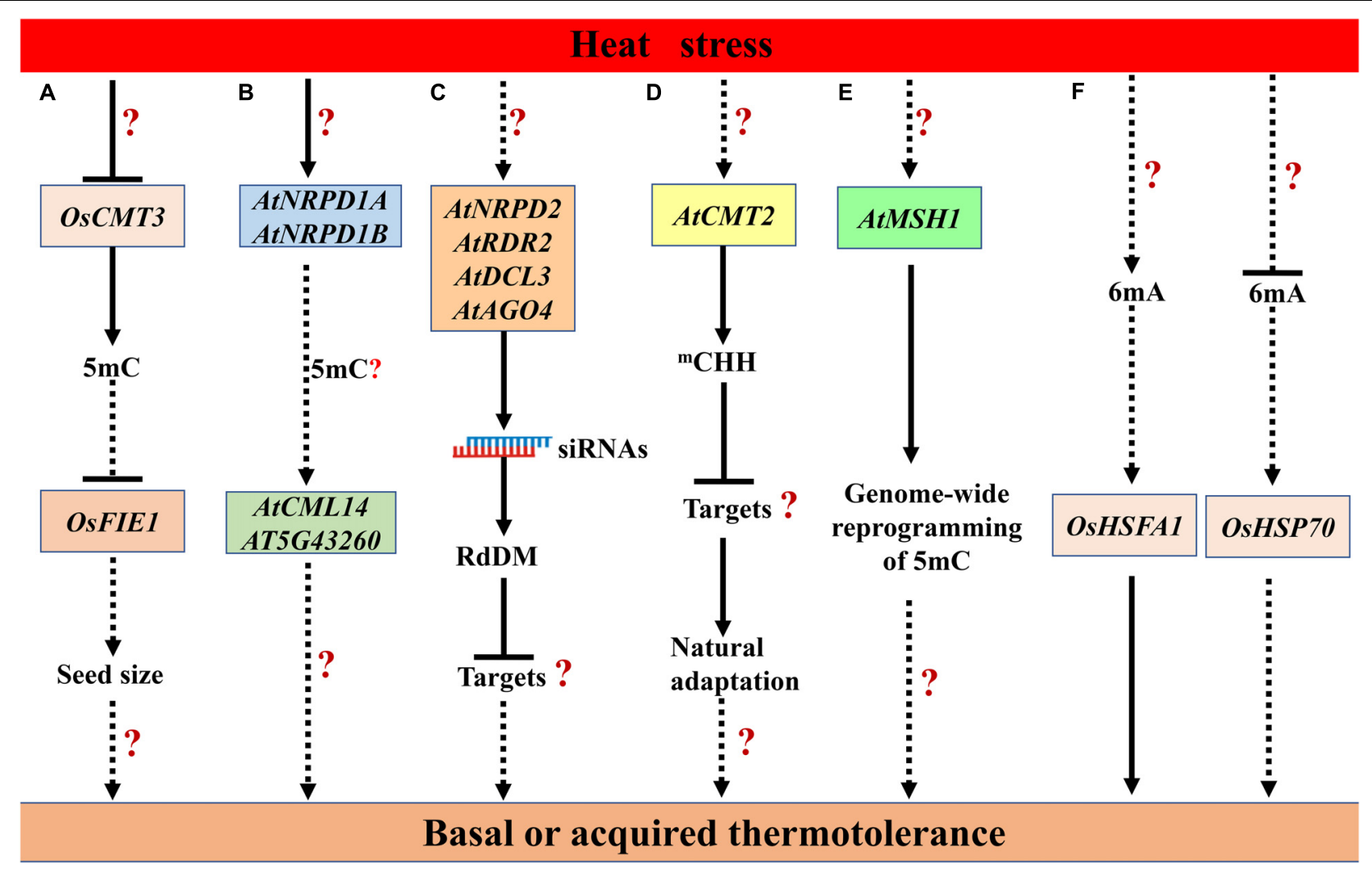

FIGURE 2 | The proposed modulation of heat stress responses by DNA methylation in plants. (A) The heat-mediated repression of OSCHROMOMETHYLASE 3 (OSCMT3) partly leads to the up-regulation of FERTILIZATION-INDEPENDENT ENDOSPERM 1 (OsFIE1), which regulates seed size under heat stress in rice (Folsom et al., 2014). (B) Heat stress up-regulates NUCLEAR RNA POLYMERASE D $1 A$ (NRPD1A) and NRPD1B, which contributes to heat-induced increase in the expression of Calmodulin-like 41 (CML41) and At5g43260 (Naydenov et al., 2015). (C) The NRPD2, RNA-DEPENDENT RNA POLYMERASE 2 (RDR2), DICER-LIKE 3 (DCL3), and ARGONAUTE 4 (AGO4)-dependent RdDM pathway is required for basal thermotolerance in Arabidopsis (Popova et al., 2013). (D) The natural variation in AtCMT2 confers changes in genome-wide $\mathrm{CHH}$-methylation pattern, which contributes to the natural adaptation to variable temperatures (Shen et al., 2014). (E) MutS HOMOLOGUE 1 (MSH1)-mediated genome-wide reprogramming may be required for thermotolerance (Virdi et al., 2016). (F) Heat stress modulates $6 \mathrm{~mA}$ levels in rice, and the changes in 6mA levels may contribute to the difference in heat tolerance between Nip and 93-11 through modulating HEAT SHOCK TRANSCRIPTION FACTOR A 1 (OSHSFA1) and HEAT SHOCK PROTEIN 70 (OsHSP70) (Zhang Q. et al., 2018). Genes are shown in boxes. The speculative regulatory paths are shown with broken arrows. Many unknown targets or steps (?) remain to be uncovered in this model.

signaling and MAPK cascade, which regulate the expression of key transcription factors. INDUCER OF CBF EXPRESSION 1 (ICE1), one of the central regulators in plant cold response, activates the C-repeat binding factors/Dehydration-responsive element-binding proteins (CBFs/DREBs), which then binds to the promoter of cold-responsive (COR) genes and actives their expression (Zhu, 2016; Gong et al., 2020). The ICE1-CBF-COR pathway plays a vital role in plant cold stress responses and the pathway is fine-tuned by multiple transcriptional and posttranslational processes (Ding et al., 2020).

DNA demethylation has been reported to play important roles in cold stress tolerance in Arabidopsis, chestnut (Castanea sativa Mill.), poplar (Populus tremula), and Cucumber (Cucumis sativus L.) (Conde et al., 2017a,b; Lai et al., 2017; Xie et al., 2019). After treated with the DNA methylation inhibitory reagent 5-azacytidine, $30.0-78.3 \%$ increases in freezing tolerance are observed in four Arabidopsis populations. Similar enhancement of freezing tolerance also occurs in $d r m 2$ mutants (Xie et al., 2019). Cold temperatures induce CsDML in chestnut and
PtaDML in poplar (Conde et al., 2017a,b). In transgenic hybrid poplars overexpressing $C s D M L$, apical bud formation is accelerated, alongside with the up-regulation of flavonoid biosynthesis enzymes and accumulation of flavonoids in the SAM and bud scales. The cold stress-mediated up-regulation of CsDML may accelerate the bud formation which is required for the survival of the apical meristem under winter (Conde et al., 2017b). In poplar, PtaDML8/10 knock-down mutants displayed delayed bud break and the targets of PtaDMLdependent DNA demethylation are involved in bud break, suggesting the essential roles of chilling-responsive PtaDMLs in the transition from winter dormancy to shoot growth in woody perennials (Conde et al., 2017a). In Cucumber, cold stress imposes a substantial and global impact on TE-related RdDM, leading to the demethylation of ${ }^{m} \mathrm{CHH}$. Besides, cold-induced differentially-methylated regions (DMRs) may be involved in the regulation of genes in ethylene biosynthesis and signaling, which contribute to the temperature-dependent sex determination in cucumber (Lai et al., 2017). However, the loss-of-function of 
MSH1 and RNA-DIRECTED DNA METHYLATION 4 (RDM4), an essential player in RdDM pathway, reduce the cold tolerance in Arabidopsis. Cold stress poses greater influences on non-CG methylation in $m s h 1$ mutants than in wild-type (Kenchanmane Raju et al., 2018). Surprisingly, RDM4 modulates the cold response by regulating the Pol II occupancy at the promoters of $C B F 2 / 3$, which is independent of RdDM pathway (Chan et al., 2016). Further forward and reverse genetic approaches as well as genome-wide profiling are needed to uncover the roles of DNA methylation-related genes in plant cold stress responses.

Prolonged cold in winter induces the epigenetic silencing of floral repressors, thus ensuring plants overwinter before flowering in spring, a process known as vernalization. Early in 1993, it has been reported that cold-treated Arabidopsis plants and Nicotiana plumbaginifolia cell line have reduced $5 \mathrm{mC}$ in their DNA compared to non-vernalized controls (Burn et al., 1993). However, the cold-induced repression of FLOWERING LOCUS C (FLC), one of the major determinants of flowering time, is associated with changes of histone methylation but not DNA methylation within the FLC locus (Jean Finnegan et al., 2005). In the biennial plant sugar beet (Beta vulgaris altissima), the $B v F L C$ locus undergoes different regulations of DNA methylation between genotypes that are resistant or sensitive to vernalization-induced bolting, while $5 \mathrm{mC}$ at specific cytosines of VERNALIZATION INSENSITIVE 3 (BvVIN3) is correlated with bolting variables (Trap-Gentil et al., 2011). Interestingly, in Brassica rapa, vernalization mediates DNA demethylation and increased expression of CASEIN KINASE II A-SUBUNIT (BrCKA2) and B-SUBUNIT (BrCKB4), two subunits of the protein kinase CK2. In BrMET1-silenced B.rapa or plants treated with 5-azacytidine, DNA methylation levels in the promoter of $B r C K A 2$ and $B r C K B 4$ are reduced and the expression levels of these two genes increase, suggesting that increased expression of $B r C K A 2$ and $B r C K B 4$ could be induced through DNA demethylation. Increased expression of $B r C K A 2$ and $B r C K B 4$ confers elevated CK2 activity and results in a shortened period of the clock gene CIRCADIAN CLOCK ASSOCIATED 1 (BrCCA1), which is an important player in perceiving photoperiod (Figure 3A; Duan et al., 2017). However, vernalization-induced demethylation is not a conserved mechanism among species. In hexaploid winter wheat, VERNALIZATION-A1 (VRN-A1) gene, a floral activator in the vernalization pathway, is methylated at CG sites in gene-body region and at non-CG sites in intron 1, which contains fragments of TEs. Vernalization increases the nonCG methylation in intron 1, which can be maintained through mitosis but reset to the pretreated level after sexual reproduction (Khan et al., 2013). Whether such hypermethylation contribute to the vernalization-induced expression of VRN-A1 remains to be dissected.

The ICE1-CBF-COR pathway is regulated by $5 \mathrm{mC}$ DNA methylation, which is associated with cold responses in different species. In crofton weed (Ageratina adenophora), the DNA methylation levels in ICE1 coding region is negatively correlated with the cold tolerance levels among different populations (Xie et al., 2015). Os03g0610900 is a homologous gene of protein kinase OPEN STOMATA 1 (OST1), which phosphorylates and stabilizes ICE1 under cold stress. Cold stress up-regulates the expression of Os03g0610900, thereby enhancing ICE1mediated cold resistance. The relationship between cold-induced $5 \mathrm{mC}$ demethylation in the promoter of Os03g0610900 and its increased expression needs further investigations (Figure 3B; Guo et al., 2019). In Hevea brasiliensis, cold stress elevates the transcriptional activities of HbICE1 as well as $H b C B F 2$, which may be associated with the DNA demethylation in their promoters (Figure 3C; Tang et al., 2018). In Arabidopsis, the variation in ICE1 $5 \mathrm{mC}$ methylation likely determines the phenotypic variation in freezing tolerance (Xie et al., 2019). Intriguingly, a recent study reports that a transgene locus harboring a reporter gene in ice1-1 genome but not the loss-offunction of ICE1 is responsible for the repression of DREB1A expression. The transgene induces hypermethylation in the DREB1A promoter through RdDM pathway, which inhibit the transcription of DREB1A (Kidokoro et al., 2020). Thus, the ICE1DREB1A regulatory module in Arabidopsis should be validated with other evidences.

Emerging reports have demonstrated that cold stress affects the DNA methylation levels of certain loci in the genome. Under cold stress, the $5 \mathrm{mC}$ level in the promoter of ALLANTOINASE $(A L N)$, a negative regulator of dormancy, is stimulated in a tissue-specific manner through non-canonical RDR6 and AGO6dependent RdDM pathway, which represses $A L N$ expression and further promotes seed dormancy (Figure 3D; Iwasaki et al., 2019). In Brassica rapa, cold acclimation decreases the DNA methylation levels in the promoter region of MITOCHONDRIAL MALATE DEHYDROGENASE (BramMDH1) and up-regulates the expression of BramMDH1, which enhances organic acids and photosynthesis to increase heat-tolerance and growth rate in Arabidopsis (Liu et al., 2017). In rose (Rosa hybrida), cold stress induces $\mathrm{CHH}$ methylation of the promoter of RhAG, an AGAMOUS homolog, which may result in the attenuated expression of RhAG. The enhanced suppression of $R h A G$ particularly contributes to the cold-mediated increase of petal number (Figure 3E; Ma N. et al., 2015). Interestingly, cold stress can induce stable methylation changes of a non-coding RNA gene and regulate some cold-responsive gene expression in Populus simonii (Song et al., 2016).

Unlike heat stress, the $6 \mathrm{~mA}$ level is significantly decreased in response to cold stress in rice. Following cold stress, the fold change in the $6 \mathrm{~mA}$ level in Nip is fourfold greater than in 9311, which may partly explain the higher tolerance of Nip to cold stress than 93-11 (Figure 3F; Zhang Q. et al., 2018). Overall, the roles of $5 \mathrm{mC}$ and $6 \mathrm{~mA}$ in plant responses to cold stress, especially freezing stress, remain largely obscure. DNA methylation play divergent roles in different species under cold stress. Highresolution bisulphite sequencing and in-depth functional analysis are required to improve our understanding on the roles of DNA methylation in plant cold stress responses.

\section{Salt Stress}

Similar as heat stress, salt stress also up-regulates $6 \mathrm{~mA}$ levels in Nip and 93-11. Under salt stress, the $6 \mathrm{~mA}$ level fold change in $93-11$ is 2.5-fold greater than in Nip (Figure 4A) (Zhang Q. et al., 2018). The roles of $6 \mathrm{~mA}$ in salt stress remain to 


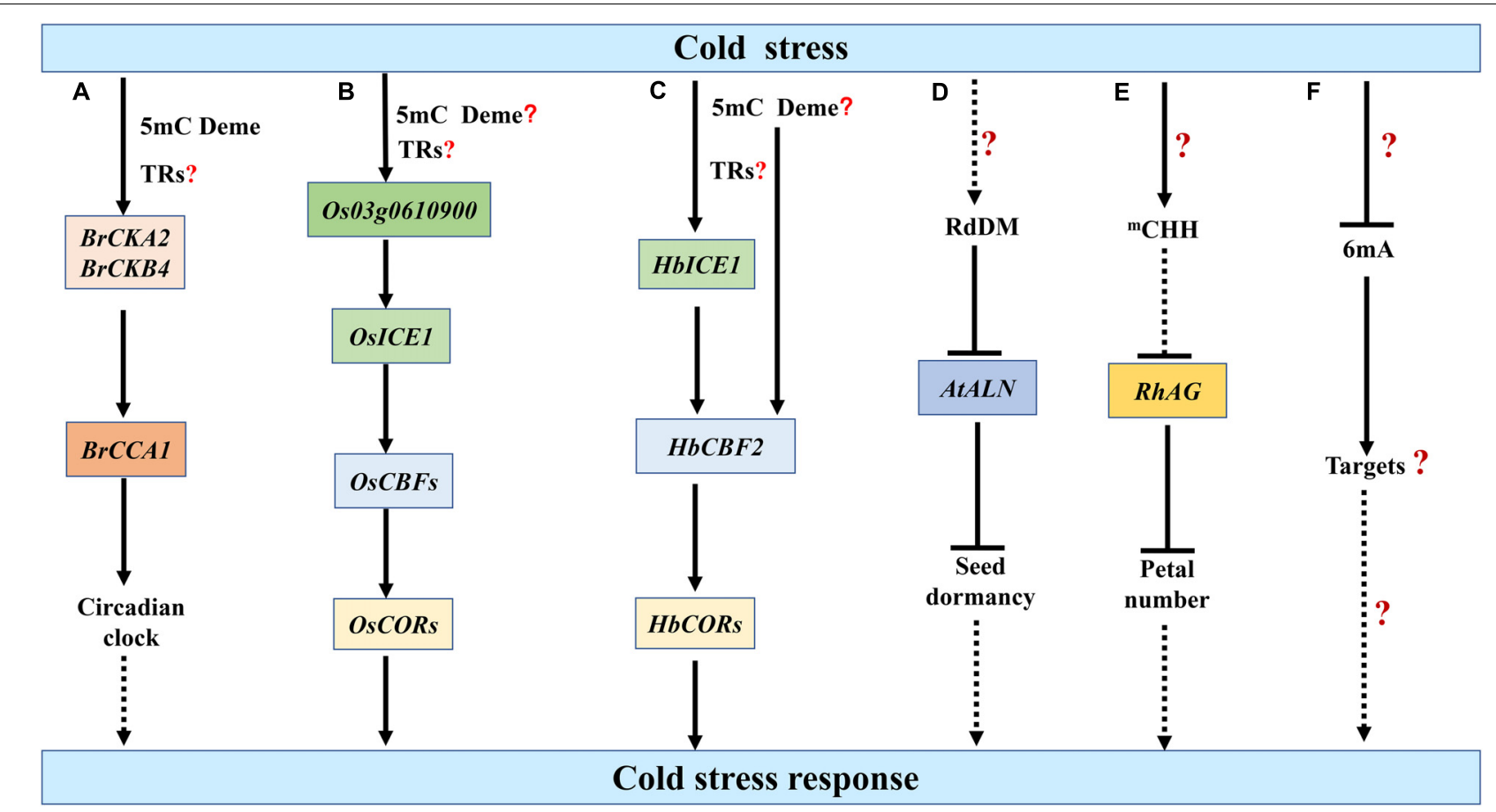

FIGURE 3 | Epigenetic regulation of plant cold stress responses by DNA methylation. (A) In Brassica rapa, prolonged cold stress mediates the demethylation and increased expression of CASEIN KINASE II A-SUBUNIT (BrCKA2) and B-SUBUNIT (BrCKB4), which may regulate cold stress response through the clock gene CIRCADIAN CLOCK ASSOCIATED 1 (BrCCA1) (Duan et al., 2017). (B) Cold stress decreases the $5 \mathrm{mC}$ in the promoter of Os03g0610900 and up-regulates its expression, thereby enhancing INDUCER OF CBF EXPRESSION 1 (ICE1)-mediated cold resistance (Guo et al., 2019). (C) In Hevea brasiliensis, cold stress elevates the transcriptional activities of HbICE1 as well as C-repeat binding factor 2 (HbCBF2), which may be associated with the DNA demethylation in their promoters (Tang et al., 2018). Whether cold-induced $5 \mathrm{mC}$ demethylation results in the up-regulation of Os03g0610900, Hb/CE1 and $\mathrm{HbCBF2}$ under cold stress remains to be elucidated (B,C). How cold-induced $5 \mathrm{mC}$ demethylation integrated with the activity of transcriptional regulators (TRs) to activate downstream gene expression also needs to be investigated (A-C). (D,E) Cold stress up-regulates the $5 \mathrm{mC}$ levels of ALLANTOINASE (ALN) in Arabidopsis and AGAMOUS homolog RhAG in rose (Rosa hybrida). The resulting repressed expression of AtALN and RhAG may be associated with seed dormancy and petal number under cold stress, respectively (Ma N. et al., 2015; Iwasaki et al., 2019). (F) Cold stress reduces the $6 \mathrm{~mA}$ levels in rice, but the roles of $6 \mathrm{~mA}$ in plant responses to cold stress remain obscure (Zhang Q. et al., 2018). $5 \mathrm{mC}$ Deme represents the demethylation of $5 \mathrm{mC}$. The speculative regulatory paths are shown with broken arrows. Many unknown targets or steps (?) remain to be investigated.

be studied. Compared with the limited research on $6 \mathrm{~mA}$, our knowledge on $5 \mathrm{mC}$ in plant salt stress responses has been accumulating. Salt stress induces diverse effects on $5 \mathrm{mC}$ in different species. For example, in wheat, salinity stress reduces the $5 \mathrm{mC}$ levels in a salinity-tolerant wheat cultivar SR3 and its progenitor parent JN177, which is less tolerant to salt stress. Among the differentially methylated salinity-responsive genes, TaFLS1, a flavonol synthase gene, and TaWRSI5, a BowmanBirk-type protease inhibitor, can enhance the salinity tolerance of Arabidopsis thaliana (Wang et al., 2014). In soybean root, bisulfite sequencing reveals that $61.2 \%$ of CGs, $39.7 \%$ of CHG, and $3.2 \%$ of CHHs are methylated under durable salt stress, which was slightly lower than those under control condition (Chen et al., 2019). In Rapeseed (Brassica napus var. oleifera), salinity stress decreases the level of $5 \mathrm{mC}$ in the salinity-tolerant cultivar Exagone but increases the methylation levels in the salinity-sensitive cultivar Toccata (Marconi et al., 2013). However, in olive (Olea europaea), salt stress induces differentially methylation changes in the $5 \mathrm{mC}$ levels of CCGG sites in the tolerant cultivar Royal, which may contribute to plant response to salt stress by slowing down the growth (Mousavi et al., 2019).
The important roles of the key players of $5 \mathrm{mC}$ in salt stress tolerance have been limitedly reported. Plants carrying mutation of RDM16, which encodes a pre-mRNA-splicing factor 3 and functions in RdDM pathway, are hypersensitive to salt stress in Arabidopsis (Huang et al., 2013). ddm1 and met1 mutant plants also show high sensitivity to salt stress (Baek et al., 2011; Yao et al., 2012). In Physcomitrella patens, PpDNMT2 accumulates in a temporal manner upon salt stress and $P p D N M T 2$ knockout plants are unable to recover from salt stress (Arya et al., 2016). Salt stress increases the expression of DNA demethylases in salt-tolerant rice variety Pokkali, which may be linked to the saltinduced demethylation, while in the salt-sensitive variety IR29, the induction of both DNA methyltransferases and demethylases may account for the lower plasticity of DNA methylation. However, the osdrm2 mutant plants display slight changes of root length and biomass under salt stress as compared to wildtype (Ferreira et al., 2015). Transgenic tobacco overexpressing AtROS1 displays enhanced tolerance to salt stress, which may be associated with enhanced expression of genes encoding enzymes of the flavonoid biosynthetic and antioxidant pathways (Bharti et al., 2015). 
Numerous researches have deciphered the effect of salt stress on the DNA methylation levels of certain loci in the genome. Salt-induced demethylation events at some salt-responsive genes can enhance salt tolerance in different species. In soybean, salt stress markedly reduces the $5 \mathrm{mC}$ levels at the promoter of MYB DOMAIN PROTEIN 84 (GMMYB84), which may be associated with its higher expression. GmMYB84 binds to the cis-regulatory sequences of $K^{+}$TRANSPORTER 1 (GmAKT1), thereby conferring salinity stress tolerance (Figure 4B; Zhang W. et al., 2020). Similarly, salt stress leads to rapid removal of $5 \mathrm{mC}$ from the promoter of OsMYB91, which may contribute to the salt-induced expression of OsMYB91. Plants over-expressing OsMYB91 show enhanced tolerance with significant increases of proline levels and enhanced capacity to scavenge active oxygen (Figure 4C; Zhu et al., 2015). Besides, salinity stress-induced methylation events of some genome loci are also involved in salt tolerance. In the shoot and root of wheat cultivar Kharchia-65, salinity stress induces a genotype- and tissue-specific increase in $5 \mathrm{mC}$ levels of HIGH-AFFINITY POTASSIUM TRANSPORTER 2;1/3 (TaHKT2;1 and TaHKT2;3) that may down-regulate their expression, thereby improving the salt tolerance (Figure 4D; Kumar et al., 2017). Interestingly, at the $2.6 \mathrm{~kb}$ upstream of the ATG start codon of AtHKT1, a putative small RNA target region is heavily methylated, which inhibits the transcription of AtHKT1. The deletion of this region or the loss of $5 \mathrm{mC}$ in this region in met1-3 mutants result in an altered expression pattern of AtHKT1 and the hypersensitivity to salt stress in plants, suggesting that this putative small RNA target region is essential for maintaining AtHKT1 expression patterns crucial for salt tolerance (Baek et al., 2011). Under salt stress, the methylation level of osa-miR393a promoter is higher in salttolerant genotype FL478 than that of salt-sensitive IR29, which may lead to a lower expression of osa-miR393a in FL478. As salt-responsive osa-miR393a is a negative regulator of salinity stress tolerance in rice, its down-regulation may increase the salt tolerance through up-regulation of the target TRANSPORT INHIBITOR RESPONSE 1 (OsTIR1) (Figure 4E; Ganie et al., 2016). Maize PROTEIN PHOSPHATASE 2C (ZmPP2C), a negative regulator of $\mathrm{ABA}$ signaling, may be repressed by salinity-induced methylation in root, while a positive effector maize GLUTATHIONE S-TRANSFERASES (ZmGST), may be up-regulated by salinity-induced demethylation in leaf. The saltinduced alteration of $5 \mathrm{mC}$ at $\mathrm{ZmPP} 2 \mathrm{C}$ and $\mathrm{ZmGST}$ may be involved in maize acclimation to salinity (Tan, 2010). Although salt induces expression changes of some methylated genes or TEs, the roles of salinity-induced methylation or demethylation changes in stress responses remain to be elucidated. For example, in rice, salt, heat and drought stresses can induce the expression of a long terminal repeat (LTR) retrotransposon, $H U O$, which is subjected to RdDM-mediated gene silencing. Multiple HUO copies may trigger genomic instability by changing global DNA methylation and small RNA biogenesis, which may result in decreased disease resistance and yield penalty (Peng et al., 2019). SpPKE1, a tomato proline-, lysine-, and glutamic-rich type gene isolated from abiotic-resistant species (Solanum pennellii LA0716), confers salt tolerance in tomato and tobacco. The detailed roles of heavy methylation in the promoter of SpPKE1 in plant salt responses remain unclear (Li et al., 2019).

\section{Drought Stress}

The drought-induced up-regulation of $5 \mathrm{mC}$ methyltransferases and demethylases has been reported in apple (Malus $\times$ domestica Borkh.), tomato, chickpea (Cicer arietinum), barley (Hordeum vulgare L.), and eggplant (Solanum melongena L.). In chickpea roots, all methyltransferases are up-regulated by drought stress (Garg et al., 2014). Drought stress increases the expression of all cytosine-5-methyltransferases and DNA demethylases except SmelCMT3a/3b in leaf tissues of eggplant (Moglia et al., 2019). Similarly, potential DNA methyltransferases and demethylases are induced by drought stress in apple, and MdCMT2 shows highest induced expression (Xu et al., 2018). SlDRM6-8, SlCMT3 and SIDNMT2 are significantly induced by dessication in tomato (Kumar et al., 2016). In a drought-tolerant barley cultivar, $H v D M E$ is also induced by drought stress (Kapazoglou et al., 2013). Further genome-wide analysis of DNA methylation in these species are needed to uncover the roles of drought-induced expressions changes of methyltransferases and demethylases in plant drought responses.

The differential regulation of $5 \mathrm{mC}$ methyltransferases and demethylases by drought stress leads to various global methylation changes in diverse species. In Arabidopsis, the drought stress-induced hypermethylation partly depends on histone variant H1.3, which can be up-regulated by water deficiency (Rutowicz et al., 2015). Although drought induces changes in DNA methylome in Arabidopsis, the methylation changes are unrelated to known transcriptome changes associated with drought stress (Ganguly et al., 2017; Van Dooren et al., 2020). Single-base resolution methylomes analysis in upland cotton by WGBS reveals that drought stress induces hypermethylation in all three sequence contexts, which are almost restored to pre-treatment levels after re-watering (Lu et al., 2017). In Populus trichocarpa, drought treatment significantly increases $5 \mathrm{mC}$ levels in upstream $2 \mathrm{~kb}$, downstream $2 \mathrm{~kb}$ and repetitive sequences (Liang et al., 2014). However, water deficit significantly reduces global $5 \mathrm{mC}$ in the model grass Brachypodium distachyon, while plants colonized by Bacillus subtilis B26 exhibit an overall increase in global DNA methylation under chronic drought, which may attribute to the B26-induced up-regulation of MET1B-like, CMT3-like and DRM2-like genes (Gagné-Bourque et al., 2015). The Bacillus subtilis B26-induced methylation changes may be associated with the increased drought stress resilience of Brachypodium. Under water-deficiency conditions, the methylation level is high and relatively stable in barley. Drought stress mainly induces new methylations in roots but initiates equal novel methylation and demethylation events in leaves. Such organ-specific methylome changes might regulate the drought resistance in barley (Chwialkowska et al., 2016).

In the model monocot rice, drought stress induces differential $5 \mathrm{mC}$ methylation alterations in drought-tolerant variety and drought-sensitive variety (Wang et al., 2011, 2016; Zheng et al., 2013). Under drought conditions, hypermethylation events occur in the drought-susceptible genotypes while drought-tolerant 


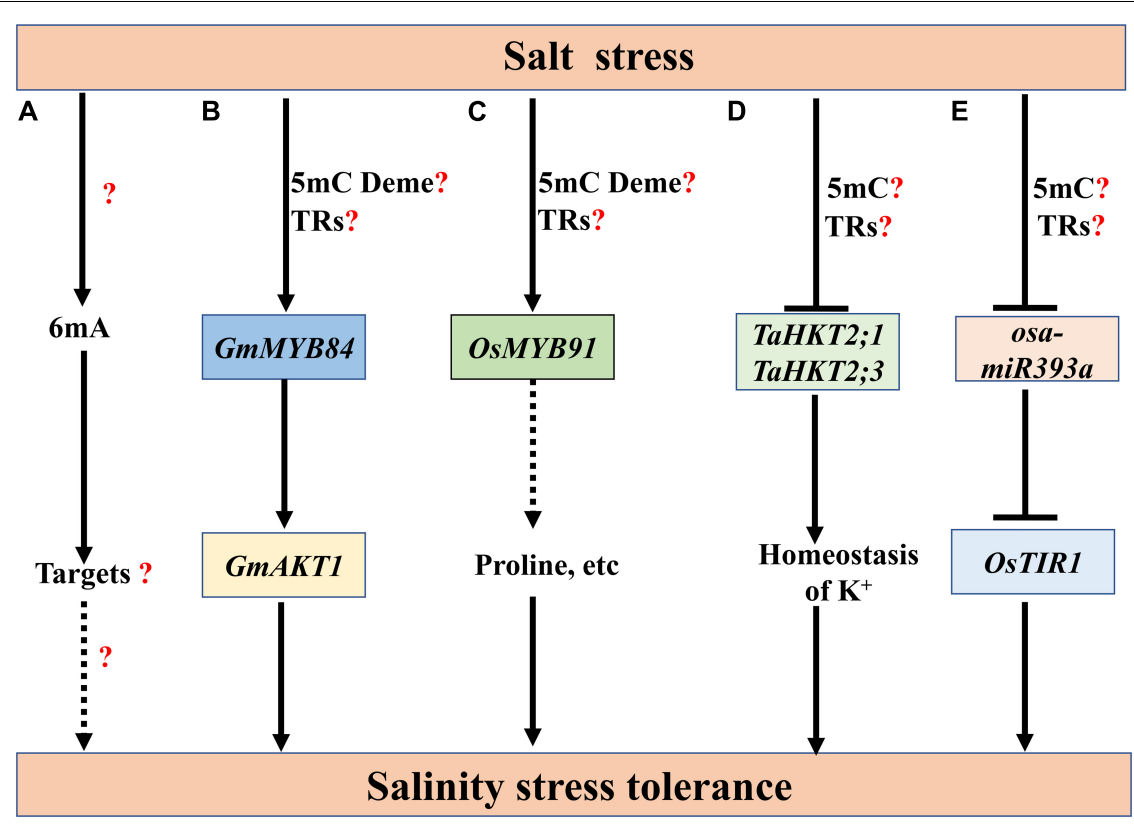

FIGURE 4 | The roles of DNA methylation in plant salt stress responses. (A) Salt stress increases the 6mA levels in rice (Zhang Q. et al., 2018), but the regulatory mechanisms underlying $6 \mathrm{~mA}$ in salt stress remain to be investigated. (B) In soybean, salt stress induces $5 \mathrm{mC}$ demethylation at the promoter of $M Y B$ DOMAIN PROTEIN 84 (GmMYB84), which may be associated with its higher expression. GmMYB84 activates K+ TRANSPORTER 1 (GmAKT1) to confer salinity stress tolerance (Zhang W. et al., 2020). (C) Salt stress leads to rapid removal of 5mC from the promoter of OsMYB91, which may contribute to the salt-induced expression of OsMYB91. Plants over-expressing OsMYB91 show enhanced tolerance with significant increases of proline levels (Zhu et al., 2015). 5mC Deme represents the demethylation of 5mC. (D) Salinity stress induces an increase in 5mC levels of HIGH-AFFINITY POTASSIUM TRANSPORTER 2;1/3 (TaHKT2; 1 and TaHKT2;3) that may downregulate their expression, thereby improving the salt tolerance. (E) Under salt stress, increased methylation levels of osa-miR393a promoter may lead to a lower expression of osa-miR393a, which may increase the salt tolerance through up-regulation of the target TRANSPORT INHIBITOR RESPONSE 1 (OSTIR1). How salt-induced $5 \mathrm{mC}$ methylation or demethylation integrated with the function of transcriptional regulators (TRs) to activate downstream gene expression remains unclear (B-E). The speculative regulatory paths are shown with broken arrows. Many unknown targets or steps (?) remain to be studied.

genotypes present hypomethylation behavior (Gayacharan and Joel, 2013). The DMR-associated genes in drought-tolerant introgression line DK151 are mainly involved in stress response, programmed cell death, and nutrient reservoir activity, which may contribute to the constitutive drought tolerance (Wang et al., 2016). Interestingly, a high proportion of multigenerational drought-induced alteration in DNA methylation status is maintained in advanced generations, which may offer the offspring improved drought adaptability in rice (Zheng et al., 2017).

Compared with heat, cold and salt stresses, our understanding regarding the drought stress-induced $5 \mathrm{mC}$ changes at droughtresponsive TEs and genes is rather limited. Single-base methylome analysis reveals that water deficit is associated with a decrease in $\mathrm{CHH}$ methylation in apple cultivars, which may result in the hypomethylated status of TEs (Xu et al., 2018). In tomato, drought stress triggers the activation of a long terminal repeat (LTR) retrotransposon Rider, which is controlled by small RNAs and RdDM pathway under normal condition. The drought-induced Rider activation might be harnessed to generate genetic and epigenetic variation for crop breeding (Benoit et al., 2019). In a genome-wide association study, a miniature inverted-repeat transposable element (MITE) inserted in the promoter of $Z m N A C 111$ is identified to be significantly associated with natural variation in maize drought tolerance.
Through the RdDM pathway, MITE represses the expression of

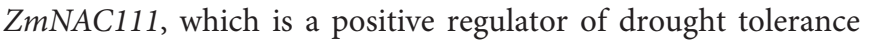
in maize (Mao et al., 2015). Drought stress decreases $\mathrm{CHH}$ methylation in the regulatory region but increases the $\mathrm{CHG}$ and $\mathrm{CHH}$ methylation in the coding region of drought-responsive gene ABSCISIC ACID STRESS RIPENING 2 (SlAsr2), which functions in alleviating restricted water availability in tomato roots (González et al., 2013).

\section{THE ROLE OF DNA METHYLATION IN ABIOTIC STRESS MEMORY}

\section{Somatic Stress Memory}

Although abiotic stresses induce various chromatin changes in plants, most epigenetic changes are transient and quickly reset to pre-stressed levels when the abiotic stresses are removed. However, some chromatin changes induced by abiotic stresses can be mitotically heritable and last for several days or even the rest time of plant life in the same generation. In Arabidopsis, recurring dehydration stresses result in transcriptional stress memory which is featured by an increase in the rate of transcription and elevated transcript levels of some stressresponse genes (Ding et al., 2012). Cold, drought and heat stress treatments can induce somatic abiotic stress memory 
with a duration of 3-10 days, which mainly involve changes in histone modification, including $\mathrm{H} 3 \mathrm{~K} 4 \mathrm{me} 2 / \mathrm{me} 3$, H3K27me3 and H3K14ac (Lamke and Bäurle, 2017; Bäurle and Trindade, 2020). The memory of vernalization-induced FLC silencing can be maintained in subsequent growth and development under warm temperatures, which is associated with the establishment and maintenance of $\mathrm{H} 3 \mathrm{~K} 27 \mathrm{me} 3$. In the pro-embryo, the seed-specific transcription factor LEAFY COTYLEDON1 (LEC1) promotes the $\mathrm{H} 3 \mathrm{~K} 27 \mathrm{me} 3$ demethylation and activation of FLC, thereby erasing the vernalization memory (Tao et al., 2017; He and $\mathrm{Li}, 2018)$. It seems that DNA methylation is not responsible for the above stress-induced somatic memory. However, in rice, the major portion of salt-induced DNA methylation or demethylation alterations remain after recovery, suggesting that the salinity-induced DNA methylation changes can remember the environmental salt stress and transmit the stress-induced epigenetic states to daughter cells through mitotic cell divisions in the present generation (Wang et al., 2015). It remains a formal possibility that some genome-loci specific $5 \mathrm{mC}$ or $6 \mathrm{~mA}$ changes may function in somatic memory of plant responses to abiotic stresses.

\section{Transgenerational Inheritance of Stress Memory}

Some abiotic stress can induce transgenerational phenotypic changes along with chromatin alterations, which can be detectable until at least one non-stressed generation (Table 1). In Arabidopsis, short-wavelength radiation (ultraviolet-C, UVC) or flagellin treatment increases the frequency of somatic homologous recombination of a transgenic reporter, which persists in the next four untreated generations (Molinier et al., 2006). It is the first report of transgenerational epigenetic inheritance in plants. Since 2006, deciphering the transgenerational memory of plant stress responses has become a fascinating research area. Some stress responses can be only transmitted to the direct progeny, which is termed as intergenerational stress memory, while some stress responses can be memorized for at least two subsequent stress-free generations, which is known as transgenerational stress memory (Lamke and Bäurle, 2017).

The intergenerational stress memory can be triggered by multiple biotic and abiotic stresses, such as flagellin (an elicitor of plant defense), ultraviolet-C, salt, cold, heat and drought stress, $\beta$-aminobutyric acid (BABA), methyl jasmonate and the bacteria Pseudomonas syringae pv tomato (PstavrRpt2) (Table 1; Johnsen et al., 2005; Kvaalen and Johnsen, 2008; Sultan et al., 2009; Boyko et al., 2010; Ito et al., 2011; Scoville et al., 2011; Slaughter et al., 2012; Iwasaki and Paszkowski, 2014; Migicovsky et al., 2014; Bilichak et al., 2015; Wibowo et al., 2016; Ganguly et al., 2017; Bose et al., 2020). Interestingly, in perennial Scots pines (Pinus sylvestris L.), environmental memory of naturally dry conditions in the parental trees drive offspring survival and growth under hot-drought conditions (Bose et al., 2020). The stress memory may protect the immediate offspring against recurring stress or offer them the potential for local acclimation to changing environments, while the resetting in the next generation may maximize growth under favorable circumstances (Crisp et al., 2016). The intergenerational stress memory may be mediated by the direct impact of environment factors on the gametogenesis, fertilization and embryo development or maternal cues that are transported into and stored in the seeds when the progeny develops in the mother plants. It remains unclear that how much of the intergenerational stress memory is due to the environmentinduced epigenetic changes. The epigenetic regulators involved in the intergenerational stress memory remain largely unidentified, except several reports of the possible roles of small RNAs and DNA methylation (Table 1; Boyko et al., 2010; Ito et al., 2011; Migicovsky et al., 2014; Bilichak et al., 2015; Wibowo et al., 2016). The hyperosmotic stress-induced responses are primarily maintained in the next generation through the female lineage due to widespread DNA glycosylase activity in the male germline, and extensively reset in the absence of stress (Wibowo et al., 2016). How the transient stress memory is maintained during meiosis in the stressed parental plants and removed or reset during the reproduction stage of the next generation remains to be investigated.

Increasing evidences indicate that many abiotic stress responses can exhibit transgenerational epigenetic inheritance (Table 1). Prolonged heat stress can induce transgenerational memory of the release of PTGS and attenuated immunity in Arabidopsis, which is mediated by a coordinated epigenetic network involving histone demethylases, heat shock transcription factors and trans-acting siRNAs (tasiRNAs) (Zhong et al., 2013; Liu et al., 2019). Cold stress and harsh UV-B treatment-induced release of TGS remain limitedly detectable for two non-stressed progeny generations (LangMladek et al., 2010). The UV-C-mediated activation of some transposons can also be maintained for two generations without the presence of stress, which requires the roles of DCL proteins (Migicovsky and Kovalchuk, 2014). Upon exposure to heavy metal stress, the $5 \mathrm{mC}$ state of a Tos17 retrotransposon is altered and shows transgenerational inheritance in rice (Cong et al., 2019). Moreover, heavy metaltransporting P-type ATPase genes (HMAs) are up-regulated under heavy metal stress, which was transgenerationally memorized in the unstressed progeny (Cong et al., 2019). Successive generations of drought stress from the tillering to grain-filling stages induces non-random epimutations and over $44.8 \%$ of drought-induced epimutations transmit their altered DNA methylation status to unstressed progeny. Epimutation-related genes directly participate in stressresponsive pathways, which may mediate rice plant's adaptation to drought stress (Zheng et al., 2017). These transgenerational memories may offer the progeny an adaptive advantage or genomic flexibility for better fitness under diverse abiotic stresses.

Stress-induced transgenerational memory has also been reported in some asexual perennial plants. In the genetically identical apomictic dandelion (Taraxacum officinale) plants, various stresses triggered considerable methylation variation throughout the genome, and many modifications were transmitted to unstressed offspring (Verhoeven et al., 2010). In two different apomictic dandelion lineages of the Taraxacum 
TABLE 1 | Examples of intergenerational and transgenerational stress memory in plants.

\begin{tabular}{|c|c|c|c|c|c|}
\hline Plants & Abiotic stress treatment & $\begin{array}{l}\text { Types of stress } \\
\text { memory }\end{array}$ & Major effects & $\begin{array}{l}\text { Possible epigenetic } \\
\text { regulators }\end{array}$ & References \\
\hline Arabidopsis thaliana & Ultraviolet-C or flagellin & Transgenerational & $\begin{array}{l}\text { Increase in homologous } \\
\text { recombination Frequency }\end{array}$ & Unknown & $\begin{array}{l}\text { (Molinier et al., } \\
\text { 2006) }\end{array}$ \\
\hline $\begin{array}{l}\text { Arabidopsis thaliana siRNA- } \\
\text { biogenesis-deficient plants }\end{array}$ & $37^{\circ} \mathrm{C}$ for $24 \mathrm{~h}$ & Intergenerational & $\begin{array}{l}\text { Retrotransposition of } \\
\text { ONSEN }\end{array}$ & siRNAs & (lto et al., 2011) \\
\hline Arabidopsis thaliana & $30^{\circ} \mathrm{C}$ for 14 days & Transgenerational & $\begin{array}{l}\text { PTGS release, early } \\
\text { flowering and attenuated } \\
\text { immunity }\end{array}$ & $\begin{array}{l}\text { H3K27me3 } \\
\text { demethylation and } \\
\text { siRNAs }\end{array}$ & $\begin{array}{l}\text { (Zhong et al., 2013; } \\
\text { Liu et al., 2019) }\end{array}$ \\
\hline $\begin{array}{l}\text { Arabidopsis thaliana } \\
\text { ddm1mom1 double } \\
\text { mutants }\end{array}$ & $37^{\circ} \mathrm{C}$ for $24 \mathrm{~h}$ & Intergenerational & Release of TGS & $\begin{array}{l}\text { Altered positioning of } \\
\text { nucleosome or others }\end{array}$ & $\begin{array}{l}\text { (Iwasaki and } \\
\text { Paszkowski, 2014) }\end{array}$ \\
\hline Arabidopsis thaliana & $50^{\circ} \mathrm{C}$ for $3 \mathrm{~h} /$ day for 5 days & Intergenerational & $\begin{array}{l}\text { Fewer but larger leaves, } \\
\text { early flowering }\end{array}$ & DCLs & $\begin{array}{l}\text { (Migicovsky et al., } \\
\text { 2014) }\end{array}$ \\
\hline Arabidopsis thaliana & UV-C stress & Transgenerational & $\begin{array}{l}\text { Increased transposon } \\
\text { expression }\end{array}$ & DCLs & $\begin{array}{l}\text { (Migicovsky and } \\
\text { Kovalchuk, 2014) }\end{array}$ \\
\hline Arabidopsis thaliana & Salt stress for 4 weeks & Intergenerational & Adaption to salt stress & $\begin{array}{l}\text { DNA methylation } \\
\text { machinery }\end{array}$ & $\begin{array}{l}\text { (Wibowo et al., } \\
\text { 2016) }\end{array}$ \\
\hline Arabidopsis thaliana & $42^{\circ} \mathrm{C}$ for $48 \mathrm{~h}$ UV-B stress & Transgenerational & $\begin{array}{l}\text { Limited inheritance of TGS } \\
\text { release }\end{array}$ & Histone acetylation & $\begin{array}{l}\text { (Lang-Mladek et al., } \\
\text { 2010) }\end{array}$ \\
\hline Arabidopsis thaliana & $\begin{array}{l}\text { Successive generations of } \\
\text { drought stress }\end{array}$ & Intergenerational & Increased seed dormancy & Unknown & $\begin{array}{l}\text { (Ganguly et al., } \\
\text { 2017) }\end{array}$ \\
\hline Arabidopsis thaliana & $\begin{array}{l}\text { Salt, UV-C, cold, heat and } \\
\text { flood stress }\end{array}$ & Intergenerational & $\begin{array}{l}\text { Increased homologous } \\
\text { recombination frequency }\end{array}$ & DCLs & (Boyko et al., 2010) \\
\hline Arabidopsis thaliana & $\begin{array}{l}\text { Grown at } 30^{\circ} \mathrm{C} \text { during } \\
\text { reproduction for two } \\
\text { generations }\end{array}$ & Transgenerational & Improved seed production & Unknown & (Whittle et al., 2009) \\
\hline Arabidopsis thaliana & $\begin{array}{l}\beta \text {-aminobutyric acid (BABA) } \\
\text { or PstavrRpt2 }\end{array}$ & Intergenerational & $\begin{array}{l}\text { Improved resistance to } \\
\text { biotic stress }\end{array}$ & Unknown & $\begin{array}{l}\text { (Slaughter et al., } \\
\text { 2012) }\end{array}$ \\
\hline $\begin{array}{l}\text { Arabidopsis thaliana } \\
\text { Solanum lycopersicum }\end{array}$ & $\begin{array}{l}\text { Herbivory, mechanical } \\
\text { damage, methyl jasmonate }\end{array}$ & Transgenerational & $\begin{array}{l}\text { Improved resistance to } \\
\text { herbivory }\end{array}$ & siRNAs & $\begin{array}{l}\text { (Rasmann et al., } \\
\text { 2012) }\end{array}$ \\
\hline Brassica rapa & $42^{\circ} \mathrm{C}$ for $3 \mathrm{~h} /$ day for 7 days & Intergenerational & Fluctuations of smRNAome & miR168 and braAGO1 & $\begin{array}{l}\text { (Bilichak et al., } \\
\text { 2015) }\end{array}$ \\
\hline Mimulus guttatus & $\begin{array}{l}\text { Simulated herbivore } \\
\text { damage }\end{array}$ & Intergenerational & Increased trichome density & Unknown & $\begin{array}{l}\text { (Scoville et al., } \\
\text { 2011) }\end{array}$ \\
\hline Oryza sativa & $\mathrm{Hg}^{2+}(50 \mu \mathrm{M} / \mathrm{L})$ for 7 days & Transgenerational & Gene expression changes & DNA methylation & $\begin{array}{l}\text { (Ou et al., 2012; } \\
\text { Cong et al., 2019) }\end{array}$ \\
\hline Oryza sativa & $\begin{array}{l}\text { Successive generations of } \\
\text { drought stress }\end{array}$ & Transgenerational & $\begin{array}{l}\text { Improved drought } \\
\text { adaptability }\end{array}$ & DNA methylation & (Zheng et al., 2017) \\
\hline Picea abies & $\begin{array}{l}\text { Daylength and temperature } \\
\text { during seed production }\end{array}$ & Intergenerational & Adaptive plasticity & Unknown & $\begin{array}{l}\text { (Johnsen et al., } \\
\text { 2005; Kvaalen and } \\
\text { Johnsen, 2008) }\end{array}$ \\
\hline Pinus sylvestris L. & Drought stress & Intergenerational & $\begin{array}{l}\text { Tolerant to hot-drought } \\
\text { conditions }\end{array}$ & Unknown & (Bose et al., 2020) \\
\hline Polygonum persicaria & Drought stress & Intergenerational & Improved drought tolerance & Unknown & (Sultan et al., 2009) \\
\hline Taraxacum officinale & $\begin{array}{l}\text { Drought and salicylic acid } \\
\text { (SA) treatment }\end{array}$ & Transgenerational & $\begin{array}{l}\text { Heritable DNA methylation } \\
\text { variation }\end{array}$ & DNA methylation & (Preite et al., 2018) \\
\hline
\end{tabular}

officinale group (Taraxacum alatum and T. hemicyclum) under drought stress or after salicylic acid (SA) treatment, heritable DNA methylation variations are observed across three generations irrespective of the initial stress treatment (Preite et al., 2018). It is needed to note that these stress-induced transgenerational DNA methylation variations in dandelions are genotype and context-specific and not targeted to specific loci (Preite et al., 2018). Unlike most annual plants, the asexual perennial plants use clonal propagation. The stress-induced DNA methylation variations may be largely inherited during mitosis, which may enable the next-generation plants to respond accurately and efficiently to adverse environment factors in some habitats (Latzel et al., 2016). How the methylation variations contribute to the phenotypic variations in asexual perennial plants remains to be investigated.

In the germline and early embryo stage, both the paternal and maternal genomes undergo extensive DNA demethylation via both active and passive demethylation pathways in mammals, which leaves very little possibility for the inheritance of stress-induced changes in methylome (Smith et al., 2012). Some examples of stress-induced transgenerational epigenetic inheritance have been reported in some animals, such as 
TABLE 2 | The divergent roles of DNA methylation in plant responses to diverse abiotic stresses.

\begin{tabular}{|c|c|c|c|c|}
\hline Plants & Abiotic stress & Changes of DNA methylation levels & Major effects & References \\
\hline Arabidopsis thaliana & Heat stress & $\begin{array}{l}\text { Altered methylation of transposon } \\
\text { remnants }\end{array}$ & $\begin{array}{l}\text { Regulation of basal } \\
\text { thermotolerance }\end{array}$ & (Popova et al., 2013) \\
\hline Arabidopsis thaliana & Heat stress & $\begin{array}{l}\text { Changes in genome-wide } \\
\mathrm{CHH} \text {-methylation pattern }\end{array}$ & $\begin{array}{l}\text { Natural adaptation to variable } \\
\text { temperatures }\end{array}$ & (Shen et al., 2014) \\
\hline Arabidopsis thaliana & Cold stress & Enhanced methylation in ALN promoter & Promoting seed dormancy & (Iwasaki et al., 2019) \\
\hline Arabidopsis thaliana & Drought stress & $\begin{array}{l}\text { Increased } 5 \mathrm{mC} \text { methylation partly } \\
\text { depending on } \mathrm{H} 1.3\end{array}$ & $\begin{array}{l}\text { Adaptive response to water } \\
\text { deficiency }\end{array}$ & (Rutowicz et al., 2015) \\
\hline $\begin{array}{l}\text { Arabidopsis thaliana } \\
\text { Ageratina adenophora }\end{array}$ & Cold stress & Variation in ICE1 methylation & $\begin{array}{l}\text { Cold tolerance divergence in } \\
\text { different accessions }\end{array}$ & (Xie et al., 2015, 2019) \\
\hline $\begin{array}{l}\text { Brachypodium } \\
\text { distachyon }\end{array}$ & Drought stress & $\begin{array}{l}\text { Decreased global } 5 \mathrm{mC} \text { while } B \text {. subtilis } \\
\text { strain B26 inoculation increases it }\end{array}$ & $\begin{array}{l}\text { Increased drought stress } \\
\text { resilience }\end{array}$ & $\begin{array}{l}\text { (Gagné-Bourque et al., } \\
\text { 2015) }\end{array}$ \\
\hline Brassica napus & Heat stress & $\begin{array}{l}\text { Increased DNA methylation in } \\
\text { heat-sensitive genotype }\end{array}$ & Adaption to heat stress & (Gao et al., 2014) \\
\hline Brassica napus & Heat stress & DNA hypomethylation & $\begin{array}{l}\text { Regulation of heat stress } \\
\text { responses in cultured } \\
\text { microspores }\end{array}$ & (Li et al., 2016) \\
\hline Brassica napus & Salt stress & $\begin{array}{l}\text { Decreased methylation in the } \\
\text { salinity-tolerant cultivar but increased } \\
\text { methylation in the salinity-sensitive cultivar }\end{array}$ & Acclimation to salt stress & (Marconi et al., 2013) \\
\hline Brassica rapa & Cold stress & $\begin{array}{l}\text { Decreased DNA methylation levels in the } \\
\text { promoter of BramMDH1 }\end{array}$ & $\begin{array}{l}\text { Increased heat-tolerance and } \\
\text { growth rate }\end{array}$ & (Liu et al., 2017) \\
\hline Brassica rapa & Cold stress & Demethylation of $B r C K A 2$ and $B r C K B 4$ & Regulation of floral transition & (Duan et al., 2017) \\
\hline Cucumis sativus & Cold stress & Demethylation at $\mathrm{CHH}$ sites & $\begin{array}{l}\text { Regulation of } \\
\text { temperature-dependent sex } \\
\text { determination }\end{array}$ & (Lai et al., 2017) \\
\hline Glycine max & Heat stress & Hypomethylation in all context & $\begin{array}{l}\text { Affecting the expression of } \\
\text { genes or TEs under heat }\end{array}$ & (Hossain et al., 2017) \\
\hline Gossypium hirsutum & Heat stress & $\begin{array}{l}\text { Reduced DNA methylation level in } \\
\text { heat-sensitive line }\end{array}$ & Microspore sterility & $\begin{array}{l}\text { (Min et al., 2014; } \\
\text { Ma et al., 2018) }\end{array}$ \\
\hline Gossypium hirsutum & Drought stress & $\begin{array}{l}\text { Global hypermethylation in all three } \\
\text { contexts }\end{array}$ & Acclimation to drought stress & (Lu et al., 2017) \\
\hline Oryza sativa & $\begin{array}{l}\text { Salt, heat and } \\
\text { drought stresses }\end{array}$ & $\begin{array}{l}\text { Activation of an LTR retrotransposon, } \\
\text { HUO }\end{array}$ & Modulation of stress responses & (Peng et al., 2019) \\
\hline Oryza sativa & $\begin{array}{l}\text { Heat, salt, cold } \\
\text { stress }\end{array}$ & $\begin{array}{l}\text { Increased } 6 \mathrm{~mA} \text { levels in heat and salt } \\
\text { stress, decreased } 6 \mathrm{~mA} \text { levels in cold } \\
\text { stress }\end{array}$ & $\begin{array}{l}\text { Regulation of plant responses } \\
\text { to environmental stresses }\end{array}$ & (Zhang Q. et al., 2018) \\
\hline Oryza sativa & Heat stress & $\begin{array}{l}\text { Decreased DNA methylation levels of } \\
\text { OsFIE1 }\end{array}$ & $\begin{array}{l}\text { Regulation of seed size under } \\
\text { heat stress }\end{array}$ & (Folsom et al., 2014) \\
\hline Oryza sativa & Salt stress & $\begin{array}{l}\text { Increased methylation level of } \\
\text { osa-miR393a promoter }\end{array}$ & Improved salt tolerance & (Ganie et al., 2016) \\
\hline Oryza sativa & Salt stress & $\begin{array}{l}\text { Decreased } 5 \mathrm{mC} \text { levels in the promoter of } \\
\text { OsMYB91 }\end{array}$ & Enhanced salt tolerance & (Xu et al., 2015) \\
\hline Oryza sativa & Drought stress & Differential $5 \mathrm{mC}$ methylation alterations & Constitutive drought tolerance & (Wang et al., 2016) \\
\hline Populus trichocarpa & Drought stress & $\begin{array}{l}\text { Increased methylation of upstream and } \\
\text { downstream } 2 \mathrm{~kb} \text {, and TEs }\end{array}$ & $\begin{array}{l}\text { Regulation of drought } \\
\text { responses }\end{array}$ & (Liang et al., 2014) \\
\hline Rosa hybrida & Cold stress & $\begin{array}{l}\text { Enhanced } \mathrm{CHH} \text { methylation of the RhAG } \\
\text { promoter. }\end{array}$ & $\begin{array}{l}\text { Regulation of floral organ } \\
\text { development }\end{array}$ & (Ma N. et al., 2015) \\
\hline Solanum lycopersicum & $\begin{array}{l}\text { Salt and drought } \\
\text { stresses }\end{array}$ & Activation of a retrotransposon, Rider & $\begin{array}{l}\text { Modulation of salt and drought } \\
\text { stress responses }\end{array}$ & (Benoit et al., 2019) \\
\hline Solanum melongena & $\begin{array}{l}\text { Salt and drought } \\
\text { stresses }\end{array}$ & $\begin{array}{l}\text { Expression changes of C5-MTases and } \\
\text { demethylases }\end{array}$ & $\begin{array}{l}\text { Response to salt and drought } \\
\text { stresses }\end{array}$ & (Moglia et al., 2019) \\
\hline Triticum aestivum & Salt stress & $\begin{array}{l}\text { Reduced methylation levels in the } \\
\text { promoter of salinity-responsive genes }\end{array}$ & $\begin{array}{l}\text { Contribute to the superior } \\
\text { salinity tolerance }\end{array}$ & (Wang et al., 2014) \\
\hline Triticum aestivum & Salt stress & $\begin{array}{l}\text { Increased } 5 \mathrm{mC} \text { levels in TaHKT2;1 and } \\
\text { TaHKT2;3 }\end{array}$ & Improved salt-tolerance ability & (Kumar et al., 2017) \\
\hline Zea mays & Salt stress & $\begin{array}{l}\text { Increased methylation of root } Z m P P 2 C \\
\text { and demethylation of leaf } Z m G S T\end{array}$ & Acclimation to salt stress & (Tan, 2010) \\
\hline Zea mays & Drought stress & $\begin{array}{l}\text { Suppression of } Z m N A C 111 \text { by MITE } \\
\text { through RdDM }\end{array}$ & $\begin{array}{l}\text { Natural variation in maize } \\
\text { drought tolerance }\end{array}$ & (Mao et al., 2015) \\
\hline
\end{tabular}


Caenorhabditis elegans, the underlying epigenetic marks are mostly histone modifications or small RNAs (Skvortsova et al., 2018). However, the DNA methylation in plants is not erased but rather epigenetically inherited during plant reproduction (Feng et al., 2010; Calarco et al., 2012; Heard and Martienssen, 2014), suggesting a potential role of DNA methylation in transgenerational memory. In the successive generations of met13 mutants deficient in maintaining CG methylation, the loss of $\mathrm{mCG}$ is found to progressively trigger new and aberrant genome-wide epigenetic patterns in a stochastic manner, such as $\mathrm{RdDM}$, decreased expression of DNA demethylases and retargeting of H3K9 methylation (Mathieu et al., 2007). Upon potato spindle tuber viroid (PSTVd) infection in tobacco, the body of PSTVd transgene is densely de novo methylated in all three contexts. However, in the viroid-free progeny plants, only ${ }^{m} \mathrm{CG}$ can be stably maintained for at least two generations independent of the RdDM triggers (Dalakouras et al., 2012). Thus, CG methylation may function as a central coordinator to secure stable abiotic transgenerational memory. In a population of epigenetic recombinant inbred lines (epiRILs) with epigenetically mosaic chromosomes consisting of wildtype and met1-3, which are nearly isogenic but highly variable at the level of DNA methylation, despite eight generations of inbreeding, unexpectedly high frequencies of non-parental methylation polymorphisms are interspersed in the genome (Reinders et al., 2009). In the F5 individual plants of $d d m 1$ epiRILs, restoration of wild-type methylation is specific to a subset of heavily methylated repeats targeted by RNA interference (RNAi) machinery (Teixeira et al., 2009). Consistent with this, in the NRPD1 complementation Arabidopsis lines, the DNA methylation of a subset of RdDM target loci can also not be restored even at $20^{\text {th }}$ generations. Many of these non-complemented DMRs overlap with epi-alleles defined in inbreeding experiments or natural accessions, which are functional in plant defense responses (Li et al., 2020). Under salt, drought and increased nutrient conditions in Arabidopsis thaliana, $d d m 1$ epiRILs exhibit phenotypic variations in root allocation, nutrient plasticity, drought and salt stress tolerance (Zhang et al., 2013; Kooke et al., 2015). These reports reinforce the idea that heritable variation in $5 \mathrm{mC}$ in epiRILs may allow the generation of epi-allelic variation, which have potential adaptive and evolutionary values. However, while the descendants of drought-stressed Arabidopsis lineages exhibit transgenerational memory of increased seed dormancy, the memory is not associated with causative changes in the DNA methylome (Ganguly et al., 2017).

Above all, although the potential roles of epigenetic regulations in transgenerational memory are undoubtable, the roles of stress-induced DNA methylation variations in the persistence of transgenerational inheritance remain to be further elucidated. The extent to which locus-specific methylation changes might contribute to the maintenance of stress memory also remains unclear. The de novo methylation of a particular region can be set up by RdDM and DNA methylation maintenance consolidates RdDM over generations in Arabidopsis thaliana, thereby establishing epigenetic memory (Kuhlmann et al., 2014). In $d d m 1$ epiRILs, several DMRs are identified as bona fide epigenetic quantitative trait loci (QTL ${ }^{\text {epi }}$ ),
BOX 1 | Future research directions.

- Which enzymes or proteins are responsible for the establishment, maintenance and erasing of $6 \mathrm{~mA}$ in plants?

- What are the roles of non-canonica RdDM pathways in plant abiotic stress response?

- How are the active and passive demethylation pathways fine-tuned by different abiotic stresses?

- What is the role of $6 \mathrm{~mA}$ in plant somatic memory and transgenerational memory?

- How to quickly identify QTL ${ }^{\text {epi }}$ from epiRILs or epi-mutation library to accelerate investigation on the epigenetic regulation of abiotic stress responses in crops?

- How to efficiently identify the key DMRs responsible for the acclimation to abiotic stresses in plants?

- How are DNA methylation changes integrated with other epigenetic alterations to confer stress tolerance?

- What are the effects of abiotic stresses-induced methylation changes on the expression of key players in the sensing and signal transduction?

- How to manipulate the somatic and transgenerational memory to improve the abiotic stress tolerance of crops without sacrificing growth?

accounting for $60-90 \%$ of the heritability for flowering time and primary root length (Cortijo et al., 2014). Whether the inheritance of DMRs induced by abiotic stress contributes to the transgenerational inheritance requires further investigation. In addition, whether abiotic stresses-induced $6 \mathrm{~mA}$ changes can be inherited and their roles in stress memory remain elusive.

\section{CONCLUDING REMARKS}

Our knowledge on the roles of DNA methylation in plant responses to abiotic stresses is accumulating in recent years. However, these discoveries regarding the roles of $5 \mathrm{mC}$ in plant responses to heat, cold, drought and salt stresses are fragmented and scattered (Table 2). The role of $6 \mathrm{~mA}$ in plant abiotic stress responses is largely unknown. More solid and comprehensive experiments are needed to elucidate the roles the abiotic stressesinduced $5 \mathrm{mC}$ and $6 \mathrm{~mA}$ changes in stress responses through regulating the expression of downstream targets. Besides, it is urgent to investigate how the stress-induced DNA methylation changes recruit or cooperate with other transcriptional regulators to modulate gene expression under abiotic stresses.

The genome-wide DNA methylation changes induced by abiotic stresses are distinct according to the intensity and duration of stress, the developmental stages, sampled tissues, genotypes and species. The diverse global changes may be attributed to the different impacts of abiotic stresses on the key components of DNA methylation among different species. To improve the tolerance of crops under abiotic stresses, we may pay more attentions to stress-induced DMRs but not the alterations in the global methylome. The mapping of epigenetic quantitative trait loci (QTL ${ }^{\mathrm{epi}}$ ) will greatly accelerate the identification of causal DMRs underlying specific phenotypes or stress tolerance in plants. Several DMRs are identified as QTL ${ }^{\text {epi }}$ controlling the variation in growth, morphology and plasticity under normal and saline conditions in $d d m 1$ epiRILs (Cortijo et al., 2014; 
Kooke et al., 2015). Linkage-linkage disequilibrium mapping has been used to decipher the QTL ${ }^{\text {epi }}$ underlying growth and wood properties in a linkage population and a natural population of Populus using MSAP-based analysis (Lu et al., 2020). These QTL ${ }^{\text {epi }}$ may be good candidates for engineering plants with better tolerance to abiotic stresses. Interestingly, two recent studies have revealed that $m s h 1$ graft-induced enhanced growth vigor or segregation of an MSH1 RNAi transgene produced nongenetic memory with multi-generational inheritance (Kundariya et al., 2020; Yang et al., 2020). The $m s h 1$ graft-induced heritable phenotype is RdDM-dependent and requires DCL2-4 to generate siRNAs. In tomato, the msh 1 grafting-enhanced growth vigor in the field can be heritable over five generations, demonstrating the huge agricultural potential of epigenetic variation (Kundariya et al., 2020). The msh1 memory produced by segregation of an MSH1 RNAi transgene, also requires RdDM pathway, which involves the function of HISTONE DEACETYLASE 6 and MET1. The MSH1 RNAi transgene-mediated methylome reprogramming contributes to the phenotypic plasticity in the transgene-free progeny, which may offer them accelerated adaptation to changing environments (Yang et al., 2020).

Our knowledge on the roles of DNA methylation in regulating the signal transduction of abiotic stress is rather limited. Only the ICE1-CBF-COR pathway in the cold signaling has been reported to be regulated by $5 \mathrm{mC}$. The influences of $5 \mathrm{mC}$ and $6 \mathrm{~mA}$ on the HSF-HSP pathway in heat responses and salt-overlysensitive (SOS) pathway in salt signaling remain to be elucidated. G-protein signaling, MAPK cascades, calcium signaling and hormone signaling are common themes in the key downstream signaling pathways under different abiotic stresses. We still need more efforts to uncover the dynamics of DNA methylation on the important players in these signaling pathways under advert abiotic circumstances.

In recent years, owing to the high efficiency and flexibility, clustered regularly interspaced short palindromic repeats (CRISPR)/CRISPR-associated protein 9 (Cas9) has been widely used in gene editing in various plant species. CRISPR/Cas9 does not induce epigenetic changes on either the target loci, flanking DNA or off-target sites (Lee et al., 2019). A CRISPR/dCas9based targeted demethylation system comprising the human demethylase TEN-ELEVEN TRANSLOCATION1 (TET1cd) and modified SunTag system has been developed with high specificity and minimal off-target effects, which has been successfully used to target the FLOWERING WAGENINGEN (FWA) promoter for demethylation to initiate a heritable late-flowering phenotype (Gallego-Bartolomé et al., 2018). Moreover, TET1-mediated demethylation has been applied for the generation of inheritable $5 \mathrm{mC}$ variation through random demethylation of the Arabidopsis genome, which results in the expression of previously silenced alleles and uncovers new phenotypic variations (Ji et al., 2018).

\section{REFERENCES}

Arya, D., Kapoor, S., and Kapoor, M. (2016). Physcomitrella patens DNA methyltransferase 2 is required for recovery from salt and osmotic stress. FEBS J 283, 556-570. doi: 10.1111/febs.13611
The fusion of the catalytic domain of 5mC DNA glycosylase ROS1 to dCas9 is also able to reactivate the silenced genes and induce targeted demethylation in a replication-independent manner (Devesa-Guerra et al., 2020). These novel tools open a new window to reactivate expression of previously silenced genes or TEs, and to develop new epi-alleles for improved abiotic stress tolerance. We may take advantage of these tools to introduce epigenetic variations for improving the adaptation to abiotic stress conditions in crops.

As listed in Box 1, many questions concerning the DNA methylation in plant abiotic stress responses remain to be answered by future researches. To further elucidate the role of $6 \mathrm{~mA}$ in plant abiotic stress responses and memory, one of the most important steps maybe the identification of the $6 \mathrm{~mA}$ methyltransferases, demethylases and the binding proteins. Plant homologs of mammalian $6 \mathrm{~mA}$ writers, erasers and readers may be potential targets. Forward genetic screens using reporter lines and reverse genetic approaches such as CRISPR/Cas9 technique will be helpful for identifying proteins involved in the establishment, maintenance and erasing of $6 \mathrm{~mA}$ in plants. Among the other questions, perhaps the most important question is: how to manipulate the somatic and transgenerational memory to improve the abiotic stress tolerance of crops without sacrificing growth? To address this question, we must identify the key DMRs or QTL ${ }^{\text {epi }}$ responsible for the acclimation to abiotic stresses in plants. Systemic screening for DMRs or QTL ${ }^{\text {epi }}$ from epiRILs and natural accessions will be powerful approaches (Quadrana and Colot, 2016). The combined application of CRISPR/Cas9 techniques and alternative inducers of DMRs or QTL ${ }^{\text {epi }}$ may enable us to engineer crops with enhanced tolerance to abiotic stresses without yield penalty.

\section{AUTHOR CONTRIBUTIONS}

$\mathrm{JL}$ and $\mathrm{ZH}$ wrote and revised the manuscript. Both authors have read and approved the final manuscript.

\section{FUNDING}

This work was supported by funding from the National Natural Science Foundation of China (91940301, 32070564, and 31600207) and Yunnan University.

\section{ACKNOWLEDGMENTS}

Due to space limitations, we apologize to our colleagues whose important works are not cited in this review.

Baek, D., Jiang, J., Chung, J. S., Wang, B., Chen, J., Xin, Z., et al. (2011). Regulated AtHKT1 gene expression by a distal enhancer element and DNA methylation in the promoter plays an important role in salt tolerance. Plant Cell Physiol. 52, 149-161. doi: 10.1093/pcp/ pcq182 
Bartee, L., Malagnac, F., and Bender, J. (2001). Arabidopsis cmt3 chromomethylase mutations block non-CG methylation and silencing of an endogenous gene. Genes Dev. 15, 1753-1758. doi: 10.1101/gad.905701

Bäurle, I., and Trindade, I. (2020). Chromatin regulation of somatic abiotic stress memory. J. Exp. Bot. 71, 5269-5279. doi: 10.1093/jxb/eraa098

Beaulaurier, J., Schadt, E. E., and Fang, G. (2019). Deciphering bacterial epigenomes using modern sequencing technologies. Nat. Rev. Genet. 20, $157-$ 172. doi: 10.1038/s41576-018-0081-3

Benoit, M., Drost, H. G., Catoni, M., Gouil, Q., Lopez-Gomollon, S., Baulcombe, D., et al. (2019). Environmental and epigenetic regulation of Rider retrotransposons in tomato. PLoS Genet. 15:e1008370. doi: 10.1371/journal. pgen. 1008370

Bharti, P., Mahajan, M., Vishwakarma, A. K., Bhardwaj, J., and Yadav, S. K. (2015). AtROS1 overexpression provides evidence for epigenetic regulation of genes encoding enzymes of flavonoid biosynthesis and antioxidant pathways during salt stress in transgenic tobacco. J. Exp. Bot. 66, 5959-5969. doi: 10.1093/jxb/ erv304

Bilichak, A., Ilnytskyy, Y., Woycicki, R., Kepeshchuk, N., Fogen, D., and Kovalchuk, I. (2015). The elucidation of stress memory inheritance in Brassica rapa plants. Front. Plant Sci. 6:5. doi: 10.3389/fpls.2015.00005

Borges, F., and Martienssen, R. A. (2015). The expanding world of small RNAs in plants. Nat. Rev. Mol. Cell Biol. 16, 727-741. doi: 10.1038/nrm4085

Bose, A. K., Moser, B., Rigling, A., Lehmann, M. M., Milcu, A., Peter, M., et al. (2020). Memory of environmental conditions across generations affects the acclimation potential of scots pine. Plant Cell Environ. 43, 1288-1299. doi: $10.1111 /$ pce. 13729

Bourc'his, D., and Voinnet, O. (2010). A small-RNA perspective on gametogenesis, fertilization, and early zygotic development. Science 330, 617-622. doi: 10.1126/ science. 1194776

Boyko, A., Blevins, T., Yao, Y., Golubov, A., Bilichak, A., Ilnytskyy, Y., et al. (2010). Transgenerational adaptation of Arabidopsis to stress requires DNA methylation and the function of Dicer-like proteins. PLoS One 5:e9514. doi: 10.1371/journal.pone.0009514

Burn, J. E., Bagnall, D. J., Metzger, J. D., Dennis, E. S., and Peacock, W. J. (1993). DNA methylation, vernalization, and the initiation of flowering. Proc. Natl. Acad. Sci. U.S.A. 90, 287-291. doi: 10.1073/pnas.90.1.287

Calarco, J. P., Borges, F., Donoghue, M. T., Van Ex, F., Jullien, P. E., Lopes, T., et al. (2012). Reprogramming of DNA methylation in pollen guides epigenetic inheritance via small RNA. Cell 151, 194-205. doi: 10.1016/j.cell.2012.09.001

Cavrak, V. V., Lettner, N., Jamge, S., Kosarewicz, A., Bayer, L. M., and Mittelsten Scheid, O. (2014). How a retrotransposon exploits the plant's heat stress response for its activation. PLoS Genet. 10:e1004115. doi: 10.1371/journal.pgen. 1004115

Chan, Z., Wang, Y., Cao, M., Gong, Y., Mu, Z., Wang, H., et al. (2016). RDM4 modulates cold stress resistance in Arabidopsis partially through the CBFmediated pathway. New Phytol. 209, 1527-1539. doi: 10.1111/nph.13727

Chellappan, P., Xia, J., Zhou, X., Gao, S., Zhang, X., Coutino, G., et al. (2010). siRNAs from miRNA sites mediate DNA methylation of target genes. Nucleic Acids Res. 38, 6883-6894. doi: 10.1093/nar/gkq590

Chen, R., Li, M., Zhang, H., Duan, L., Sun, X., Jiang, Q., et al. (2019). Continuous salt stress-induced long non-coding RNAs and DNA methylation patterns in soybean roots. BMC Genomics 20:730. doi: 10.1186/s12864-019-6101-7

Chwialkowska, K., Nowakowska, U., Mroziewicz, A., Szarejko, I., and Kwasniewski, M. (2016). Water-deficiency conditions differently modulate the methylome of roots and leaves in barley (Hordeum vulgare L.). J. Exp. Bot. 67, 1109-1121. doi: 10.1093/jxb/erv552

Cokus, S. J., Feng, S., Zhang, X., Chen, Z., Merriman, B., Haudenschild, C. D., et al. (2008). Shotgun bisulphite sequencing of the Arabidopsis genome reveals DNA methylation patterning. Nature 452, 215-219. doi: 10.1038/nature06745

Conde, D., Le Gac, A. L., Perales, M., Dervinis, C., Kirst, M., Maury, S., et al. (2017a). Chilling-responsive DEMETER-LIKE DNA demethylase mediates in poplar bud break. Plant Cell Environ. 40, 2236-2249. doi: 10.1111/pce.13019

Conde, D., Moreno-Cortés, A., Dervinis, C., Ramos-Sánchez, J. M., Kirst, M., Perales, M., et al. (2017b). Overexpression of DEMETER, a DNA demethylase, promotes early apical bud maturation in poplar. Plant Cell Environ. 40, 28062819. doi: 10.1111/pce.13056

Cong, W., Miao, Y., Xu, L., Zhang, Y., Yuan, C., Wang, J., et al. (2019). Transgenerational memory of gene expression changes induced by heavy metal stress in rice (Oryza sativa L.). BMC Plant Biol. 19:282. doi: 10.1186/s12870019-1887-7

Cortijo, S., Wardenaar, R., Colome-Tatche, M., Gilly, A., Etcheverry, M., Labadie, K., et al. (2014). Mapping the epigenetic basis of complex traits. Science 343, 1145-1148. doi: 10.1126/science.1248127

Crisp, P. A., Ganguly, D., Eichten, S. R., Borevitz, J. O., and Pogson, B. J. (2016). Reconsidering plant memory: intersections between stress recovery, RNA turnover, and epigenetics. Sci. Adv. 2:e1501340. doi: 10.1126/sciadv.1501340

Cuerda-Gil, D., and Slotkin, R. K. (2016). Non-canonical RNA-directed DNA methylation. Nat. Plants 2:16163. doi: 10.1038/nplants.2016.163

Dalakouras, A., Dadami, E., Zwiebel, M., Krczal, G., and Wassenegger, M. (2012). Transgenerational maintenance of transgene body CG but not CHG and CHH methylation. Epigenetics 7, 1071-1078. doi: 10.4161/epi.21644

Dasgupta, P., and Chaudhuri, S. (2019). Analysis of DNA methylation profile in plants by Chop-PCR. Methods Mol. Biol. 1991, 79-90. doi: 10.1007/978-1-49399458-8_9

Devesa-Guerra, I., Morales-Ruiz, T., Pérez-Roldán, J., Parrilla-Doblas, J. T., Dorado-León, M., García-Ortiz, M. V., et al. (2020). DNA methylation editing by CRISPR-guided excision of 5-methylcytosine. J. Mol. Biol. 432, 2204-2216. doi: 10.1016/j.jmb.2020.02.007

Ding, Y., Fromm, M., and Avramova, Z. (2012). Multiple exposures to drought 'train' transcriptional responses in Arabidopsis. Nat. Commun. 3:740. doi: 10. 1038/ncomms 1732

Ding, Y., Shi, Y., and Yang, S. (2020). Molecular regulation of plant responses to environmental temperatures. Mol. Plant 13, 544-564. doi: 10.1016/j.molp.2020. 02.004

Du, J., Johnson, L. M., Groth, M., Feng, S., Hale, C. J., Li, S., et al. (2014). Mechanism of DNA methylation-directed histone methylation by KRYPTONITE. Mol. Cell. 55, 495-504. doi: 10.1016/j.molcel.2014.06.009

Du, J., Zhong, X., Bernatavichute, Y. V., Stroud, H., Feng, S., Caro, E., et al. (2012). Dual binding of chromomethylase domains to H3K9me2-containing nucleosomes directs DNA methylation in plants. Cell 151, 167-180. doi: 10. 1016/j.cell.2012.07.034

Duan, W., Zhang, H., Zhang, B., Wu, X., Shao, S., Li, Y., et al. (2017). Role of vernalization-mediated demethylation in the floral transition of Brassica rapa. Planta 245, 227-233. doi: 10.1007/s00425-016-2622-3

Feng, S. H., Jacobsen, S. E., and Reik, W. (2010). Epigenetic reprogramming in plant and animal development. Science 330, 622-627. doi: 10.1126/science. 1190614

Ferreira, L. J., Azevedo, V., Maroco, J., Oliveira, M. M., and Santos, A. P. (2015). Salt tolerant and sensitive rice varieties display differential methylome flexibility under salt stress. PLoS One 10:e0124060. doi: 10.1371/journal.pone.01 24060

Finnegan, E. J., Peacock, W. J., and Dennis, E. S. (1996). Reduced DNA methylation in Arabidopsis thaliana results in abnormal plant development. Proc. Natl. Acad. Sci. U.S.A. 93, 8449-8454. doi: 10.1073/pnas.93.16.8449

Folsom, J. J., Begcy, K., Hao, X., Wang, D., and Walia, H. (2014). Rice FertilizationIndependent Endosperm1 regulates seed size under heat stress by controlling early endosperm development. Plant Physiol. 165, 238-248. doi: 10.1104/pp. 113.232413

Gagné-Bourque, F., Mayer, B. F., Charron, J. B., Vali, H., Bertrand, A., and Jabaji, S. (2015). Accelerated growth rate and increased drought stress resilience of the model grass Brachypodium distachyon colonized by Bacillus subtilis B26. PLoS One 10:e0130456. doi: 10.1371/journal.pone.0130456

Gallego-Bartolomé, J., Gardiner, J., Liu, W., Papikian, A., Ghoshal, B., Kuo, H. Y., et al. (2018). Targeted DNA demethylation of the Arabidopsis genome using the human TET1 catalytic domain. Proc. Natl. Acad. Sci. U.S.A. 115, E2125-E2134. doi: 10.1073/pnas.1716945115

Ganguly, D. R., Crisp, P. A., Eichten, S. R., and Pogson, B. J. (2017). The Arabidopsis DNA methylome is stable under transgenerational drought stress. Plant Physiol. 175, 1893-1912. doi: 10.1104/pp.17.00744

Ganie, S. A., Dey, N., and Mondal, T. K. (2016). Promoter methylation regulates the abundance of osa-miR393a in contrasting rice genotypes under salinity stress. Funct. Integr. Genomics 16, 1-11. doi: 10.1007/s10142-015-0460-1

Gao, G., Li, J., Li, H., Li, F., Xu, K., Yan, G., et al. (2014). Comparison of the heat stress induced variations in DNA methylation between heat-tolerant and heat-sensitive rapeseed seedlings. Breed. Sci. 64, 125-133. doi: 10.1270/jsbbs. 64.125 
Garg, R., Kumari, R., Tiwari, S., and Goyal, S. (2014). Genomic survey, gene expression analysis and structural modeling suggest diverse roles of DNA methyltransferases in legumes. PLoS One 9:e88947. doi: 10.1371/journal.pone. 0088947

Gayacharan, and Joel, A. J. (2013). Epigenetic responses to drought stress in rice (Oryza sativa L.). Physiol. Mol. Biol. Plants 19, 379-387. doi: 10.1007/s12298013-0176-4

Gong, Z., Morales-Ruiz, T., Ariza, R. R., Roldán-Arjona, T., David, L., and Zhu, J. K. (2002). ROS1, a repressor of transcriptional gene silencing in Arabidopsis, encodes a DNA glycosylase/lyase. Cell 111, 803-814. doi: 10.1016/s00928674(02)01133-9

Gong, Z., Xiong, L., Shi, H., Yang, S., Herrera-Estrella, L. R., Xu, G., et al. (2020). Plant abiotic stress response and nutrient use efficiency. Sci. China Life Sci. 63, 635-674. doi: 10.1007/s11427-020-1683-x

González, R. M., Ricardi, M. M., and Iusem, N. D. (2013). Epigenetic marks in an adaptive water stress-responsive gene in tomato roots under normal and drought conditions. Epigenetics 8, 864-872. doi: 10.4161/epi.25524

Guevara, M., De María, N., Sáez-Laguna, E., Vélez, M. D., Cervera, M. T., and Cabezas, J. A. (2017). Analysis of DNA cytosine methylation patterns using methylation-sensitive amplification polymorphism (MSAP). Methods Mol. Biol. 1456, 99-112. doi: 10.1007/978-1-4899-7708-3_9

Guo, H., Wu, T., Li, S., He, Q., Yang, Z., Zhang, W., et al. (2019). The methylation patterns and transcriptional responses to chilling stress at the seedling stage in rice. Int. J. Mol. Sci. 20:5089. doi: 10.3390/ijms20205089

Harris, C. J., Scheibe, M., Wongpalee, S. P., Liu, W., Cornett, E. M., Vaughan, R. M., et al. (2018). A DNA methylation reader complex that enhances gene transcription. Science 362, 1182-1186. doi: 10.1126/science.aar7854

He, Y., and Li, Z. (2018). Epigenetic environmental memories in plants: establishment, maintenance, and reprogramming. Trends Genet. 34, 856-866. doi: 10.1016/j.tig.2018.07.006

Heard, E., and Martienssen, R. A. (2014). Transgenerational epigenetic inheritance: myths and mechanisms. Cell 157, 95-109. doi: 10.1016/j.cell.2014.02.045

Hossain, M. S., Kawakatsu, T., Kim, K. D., Zhang, N., Nguyen, C. T., Khan, S. M., et al. (2017). Divergent cytosine DNA methylation patterns in single-cell, soybean root hairs. New Phytol. 214, 808-819. doi: 10.1111/nph.14421

Hu, L., Li, N., Xu, C., Zhong, S., Lin, X., Yang, J., et al. (2014). Mutation of a major CG methylase in rice causes genome-wide hypomethylation, dysregulated genome expression, and seedling lethality. Proc. Natl. Acad. Sci. U.S.A. 111, 10642-10647. doi: 10.1073/pnas.1410761111

Huang, C. F., Miki, D., Tang, K., Zhou, H. R., Zheng, Z., Chen, W., et al. (2013). A Pre-mRNA-splicing factor is required for RNA-directed DNA methylation in Arabidopsis. PLoS Genet. 9:e1003779. doi: 10.1371/journal.pgen.1003779

Ito, H., Gaubert, H., Bucher, E., Mirouze, M., Vaillant, I., and Paszkowski, J. (2011). An siRNA pathway prevents transgenerational retrotransposition in plants subjected to stress. Nature 472, 115-119. doi: 10.1038/nature09861

Iwasaki, M., Hyvärinen, L., Piskurewicz, U., and Lopez-Molina, L. (2019). Non-canonical RNA-directed DNA methylation participates in maternal and environmental control of seed dormancy. eLife 8:e37434. doi: 10.7554/eLife. 37434

Iwasaki, M., and Paszkowski, J. (2014). Identification of genes preventing transgenerational transmission of stress-induced epigenetic states. Proc. Natl. Acad. Sci. U.S.A. 111, 8547-8552. doi: 10.1073/pnas.1402275111

Jackson, J. P., Lindroth, A. M., Cao, X., and Jacobsen, S. E. (2002). Control of CpNpG DNA methylation by the KRYPTONITE histone $\mathrm{H} 3$ methyltransferase. Nature 416, 556-560. doi: 10.1038/nature731

Jean Finnegan, E., Kovac, K. A., Jaligot, E., Sheldon, C. C., James Peacock, W., and Dennis, E. S. (2005). The downregulation of FLOWERING LOCUS C (FLC) expression in plants with low levels of DNA methylation and by vernalization occurs by distinct mechanisms. Plant J. 44, 420-432. doi: 10.1111/j.1365-313X. 2005.02541.x

Ji, L., Jordan, W. T., Shi, X., Hu, L., He, C., and Schmitz, R. J. (2018). TET-mediated epimutagenesis of the Arabidopsis thaliana methylome. Nat. Commun. 9:895. doi: 10.1038/s41467-018-03289-7

Jiang, Z., Zhou, X., Tao, M., Yuan, F., Liu, L., Wu, F., et al. (2019). Plant cell-surface GIPC sphingolipids sense salt to trigger $\mathrm{Ca}^{2+}$ influx. Nature 572, 341-346. doi: 10.1038/s41586-019-1449-z

Johnsen, O., Daehlen, O. G., Ostreng, G., and Skrøppa, T. (2005). Daylength and temperature during seed production interactively affect adaptive performance of Picea abies progenies. New Phytol. 168, 589-596. doi: 10.1111/j.1469-8137. 2005.01538.x

Jung, J. H., Domijan, M., Klose, C., Biswas, S., Ezer, D., Gao, M., et al. (2016). Phytochromes function as thermosensors in Arabidopsis. Science 354, 886-889. doi: 10.1126/science.aaf6005

Kapazoglou, A., Drosou, V., Argiriou, A., and Tsaftaris, A. S. (2013). The study of a barley epigenetic regulator, $H v D M E$, in seed development and under drought. BMC Plant Biol. 13:172. doi: 10.1186/1471-2229-13-172

Kenchanmane Raju, S. K., Shao, M. R., Wamboldt, Y., and Mackenzie, S. (2018). Epigenomic plasticity of Arabidopsis $m s h 1$ mutants under prolonged cold stress. Plant Direct. 2:e00079. doi: 10.1002/pld3.79

Khan, A. R., Enjalbert, J., Marsollier, A. C., Rousselet, A., Goldringer, I., and Vitte, C. (2013). Vernalization treatment induces site-specific DNA hypermethylation at the VERNALIZATION-A1 (VRN-A1) locus in hexaploid winter wheat. BMC Plant Biol. 13:209. doi: 10.1186/1471-2229-13-209

Khraiwesh, B., Arif, M. A., Seumel, G. I., Ossowski, S., Weigel, D., Reski, R., et al. (2010). Transcriptional control of gene expression by microRNAs. Cell 140, 111-122. doi: 10.1016/j.cell.2009.12.023

Kidokoro, S., Kim, J. S., Ishikawa, T., Suzuki, T., Shinozaki, K., and YamaguchiShinozaki, K. (2020). DREB1A/CBF3 is repressed by transgene-induced DNA methylation in the Arabidopsis ice1 -1 mutant. Plant Cell 32, 1035-1048. doi: 10.1105/tpc.19.00532

Kim, J., Kim, J. H., Richards, E. J., Chung, K. M., and Woo, H. R. (2014). Arabidopsis VIM proteins regulate epigenetic silencing by modulating DNA methylation and histone modification in cooperation with MET1. Mol. Plant 7, 1470-1485. doi: $10.1093 / \mathrm{mp} / \mathrm{ssu} 079$

Kooke, R., Johannes, F., Wardenaar, R., Becker, F., Etcheverry, M., Colot, V., et al. (2015). Epigenetic basis of morphological variation and phenotypic plasticity in Arabidopsis thaliana. Plant Cell 27, 337-348. doi: 10.1105/tpc.114.133025

Kuhlmann, M., Finke, A., Mascher, M., and Mette, M. F. (2014). DNA methylation maintenance consolidates RNA-directed DNA methylation and transcriptional gene silencing over generations in Arabidopsis thaliana. Plant J. 80, 269-281. doi: $10.1111 /$ tpj.12630

Kumar, R., Chauhan, P. K., and Khurana, A. (2016). Identification and expression profiling of DNA methyltransferases during development and stress conditions in solanaceae. Funct. Integr. Genomics 16, 513-528. doi: 10.1007/s10142-0160502-3

Kumar, S., Beena, A. S., Awana, M., and Singh, A. (2017). Salt-induced tissuespecific cytosine methylation downregulates expression of HKT genes in contrasting wheat (Triticum aestivum L.) genotypes. DNA Cell Biol. 36, 283-294. doi: 10.1089/dna.2016.3505

Kumar, S. V., and Wigge, P. A. (2010). H2A.Z-containing nucleosomes mediate the thermosensory response in Arabidopsis. Cell 140, 136-147. doi: 10.1016/j. cell.2009.11.006

Kundariya, H., Yang, X., Morton, K., Sanchez, R., Axtell, M. J., Hutton, S. F., et al. (2020). MSH1-induced heritable enhanced growth vigor through grafting is associated with the RdDM pathway in plants. Nat. Commun. 11:5343. doi: 10.1038/s41467-020-19140-x

Kvaalen, H., and Johnsen, O. (2008). Timing of bud set in Picea abies is regulated by a memory of temperature during zygotic and somatic embryogenesis. New Phytol. 177, 49-59. doi: 10.1111/j.1469-8137.2007.02222.x

Lai, Y. S., Zhang, X., Zhang, W., Shen, D., Wang, H., Xia, Y., et al. (2017). The association of changes in DNA methylation with temperature-dependent sex determination in cucumber. J. Exp. Bot. 68, 2899-2912. doi: 10.1093/jxb/ erx144

Lamke, J., and Bäurle, I. (2017). Epigenetic and chromatin-based mechanisms in environmental stress adaptation and stress memory in plants. Genome Biol. 18:124. doi: 10.1186/s13059-017-1263-6

Lang-Mladek, C., Popova, O., Kiok, K., Berlinger, M., Rakic, B., Aufsatz, W., et al. (2010). Transgenerational inheritance and resetting of stress-induced loss of epigenetic gene silencing in Arabidopsis. Mol. Plant 3, 594-602. doi: 10.1093/ $\mathrm{mp} / \mathrm{ssq} 014$

Latzel, V., Rendina González, A. P., and Rosenthal, J. (2016). Epigenetic memory as a basis for intelligent behavior in clonal plants. Front. Plant Sci. 7:1354. doi: $10.3389 /$ fpls.2016.01354

Law, J. A., and Jacobsen, S. E. (2010). Establishing, maintaining and modifying DNA methylation patterns in plants and animals. Nat. Rev. Genet. 11, 204-220. doi: $10.1038 / \mathrm{nrg} 2719$ 
Lee, J. H., Mazarei, M., Pfotenhauer, A. C., Dorrough, A. B., Poindexter, M. R., Hewezi, T., et al. (2019). Epigenetic footprints of CRISPR/Cas9-mediated genome editing in plants. Front. Plant Sci. 10:1720. doi: 10.3389/fpls.2019. 01720

Legris, M., Klose, C., Burgie, E. S., Rojas, C. C., Neme, M., Hiltbrunner, A., et al. (2016). Phytochrome B integrates light and temperature signals in Arabidopsis. Science 354, 897-900. doi: 10.1126/science.aaf5656

Lei, M., Zhang, H., Julian, R., Tang, K., Xie, S., and Zhu, J. K. (2015). Regulatory link between DNA methylation and active demethylation in Arabidopsis. Proc. Natl. Acad. Sci. U.S.A. 112, 3553-3557. doi: 10.1073/pnas.1502279112

Lesk, C., Rowhani, P., and Ramankutty, N. (2016). Influence of extreme weather disasters on global crop production. Nature 529, 84-87. doi: 10.1038/ nature16467

Li, J., Chen, C., Wei, J., Pan, Y., Su, C., and Zhang, X. (2019). SpPKE1, a multiple stress-responsive gene confers salt tolerance in tomato and tobacco. Int. J. Mol. Sci. 20:2478. doi: 10.3390/ijms20102478

Li, J., Huang, Q., Sun, M., Zhang, T., Li, H., Chen, B., et al. (2016). Global DNA methylation variations after short-term heat shock treatment in cultured microspores of Brassica napus cv. Topas. Sci. Rep. 6:38401. doi: 10.1038/ srep38401

Li, J., Yang, D. L., Huang, H., Zhang, G., He, L., Pang, J., et al. (2020). Epigenetic memory marks determine epiallele stability at loci targeted by de novo DNA methylation. Nat. Plants 6, 661-674. doi: 10.1038/s41477-020-0671-x

Li, X., Zhu, J., Hu, F., Ge, S., Ye, M., Xiang, H., et al. (2012). Single-base resolution maps of cultivated and wild rice methylomes and regulatory roles of DNA methylation in plant gene expression. BMC Genomics 13:300. doi: 10.1186/ 1471-2164-13-300

Liang, D., Zhang, Z., Wu, H., Huang, C., Shuai, P., Ye, C. Y., et al. (2014). Singlebase-resolution methylomes of Populus trichocarpa reveal the association between DNA methylation and drought stress. BMC Genet. 15(Suppl. 1):S9. doi: 10.1186/1471-2156-15-s1-s9

Liang, Z., Geng, Y., and Gu, X. (2018a). Adenine methylation: new epigenetic marker of DNA and mRNA. Mol. Plant 11, 1219-1221. doi: 10.1016/j.molp. 2018.08.001

Liang, Z., Shen, L., Cui, X., Bao, S., Geng, Y., Yu, G., et al. (2018b). DNA $N^{6}$ adenine methylation in Arabidopsis thaliana. Dev. Cell 45, 406.e3-416.e3. doi: 10.1016/j.devcel.2018.03.012

Lindroth, A. M., Cao, X., Jackson, J. P., Zilberman, D., Mccallum, C. M., Henikoff, S., et al. (2001). Requirement of CHROMOMETHYLASE3 for maintenance of CpXpG methylation. Science 292, 2077-2080. doi: 10.1126/science.10 59745

Liu, J., Feng, L., Gu, X., Deng, X., Qiu, Q., Li, Q., et al. (2019). An H3K27me3 demethylase-HSFA2 regulatory loop orchestrates transgenerational thermomemory in Arabidopsis. Cell Res. 29, 379-390. doi: 10.1038/s41422-019$0145-8$

Liu, J., Feng, L., Li, J., and He, Z. (2015). Genetic and epigenetic control of plant heat responses. Front. Plant Sci. 6:267. doi: 10.3389/fpls.2015.00267

Liu, R., and Lang, Z. (2020). The mechanism and function of active DNA demethylation in plants. J. Integr. Plant Biol. 62, 148-159. doi: 10.1111/jipb. 12879

Liu, T., Li, Y., Duan, W., Huang, F., and Hou, X. (2017). Cold acclimation alters DNA methylation patterns and confers tolerance to heat and increases growth rate in Brassica rapa. J. Exp. Bot. 68, 1213-1224. doi: 10.1093/jxb/erw496

Lobell, D. B., Schlenker, W., and Costa-Roberts, J. (2011). Climate trends and global crop production since 1980. Science 333, 616-620. doi: 10.1126/science. 1204531

Long, J. C., Xia, A. A., Liu, J. H., Jing, J. L., Wang, Y. Z., Qi, C. Y., et al. (2019). Decrease in DNA methylation 1 (DDM1) is required for the formation of mCHH islands in maize. J. Integr. Plant Biol. 61, 749-764. doi: 10.1111/jipb. 12733

Lu, W., Xiao, L., Quan, M., Wang, Q., El-Kassaby, Y. A., Du, Q., et al. (2020). Linkage-linkage disequilibrium dissection of the epigenetic quantitative trait loci (epiQTLs) underlying growth and wood properties in Populus. New Phytol. 225, 1218-1233. doi: 10.1111/nph.16220

Lu, X., Wang, X., Chen, X., Shu, N., Wang, J., Wang, D., et al. (2017). Singlebase resolution methylomes of upland cotton (Gossypium hirsutum L.) reveal epigenome modifications in response to drought stress. BMC Genomics 18:297. doi: $10.1186 /$ s12864-017-3681-y
Ma, N., Chen, W., Fan, T., Tian, Y., Zhang, S., Zeng, D., et al. (2015). Low temperature-induced DNA hypermethylation attenuates expression of $R h A G$, an AGAMOUS homolog, and increases petal number in rose (Rosa hybrida). BMC Plant Biol. 15:237. doi: 10.1186/s12870-015-0623-1

Ma, Y., Dai, X., Xu, Y., Luo, W., Zheng, X., Zeng, D., et al. (2015). COLD1 confers chilling tolerance in rice. Cell 160, 1209-1221. doi: 10.1016/j.cell.2015.01.046

Ma, Y., Min, L., Wang, M., Wang, C., Zhao, Y., Li, Y., et al. (2018). Disrupted genome methylation in response to high temperature has distinct affects on microspore abortion and anther indehiscence. Plant Cell 30, 1387-1403. doi: $10.1105 /$ tpc. 18.00074

Mao, H., Wang, H., Liu, S., Li, Z., Yang, X., Yan, J., et al. (2015). A transposable element in a NAC gene is associated with drought tolerance in maize seedlings. Nat. Commun. 6:8326. doi: 10.1038/ncomms 9326

Marconi, G., Pace, R., Traini, A., Raggi, L., Lutts, S., Chiusano, M., et al. (2013). Use of MSAP markers to analyse the effects of salt stress on DNA methylation in rapeseed (Brassica napus var. oleifera). PLoS One 8:e75597. doi: 10.1371/journal. pone. 0075597

Marí-Ordóñez, A., Marchais, A., Etcheverry, M., Martin, A., Colot, V., and Voinnet, O. (2013). Reconstructing de novo silencing of an active plant retrotransposon. Nat. Genet. 45, 1029-1039. doi: 10.1038/ng.2703

Mathieu, O., Reinders, J., Caikovski, M., Smathajitt, C., and Paszkowski, J. (2007). Transgenerational stability of the Arabidopsis epigenome is coordinated by CG methylation. Cell 130, 851-862. doi: 10.1016/j.cell.2007.07.007

McCue, A. D., Panda, K., Nuthikattu, S., Choudury, S. G., Thomas, E. N., and Slotkin, R. K. (2015). ARGONAUTE 6 bridges transposable element mRNAderived siRNAs to the establishment of DNA methylation. EMBO J. 34, 20-35. doi: $10.15252 / \mathrm{embj} .201489499$

Migicovsky, Z., and Kovalchuk, I. (2014). Transgenerational changes in plant physiology and in transposon expression in response to UV-C stress in Arabidopsis thaliana. Plant Signal. Behav. 9:e976490. doi: 10.4161/15592324. 2014.976490

Migicovsky, Z., Yao, Y., and Kovalchuk, I. (2014). Transgenerational phenotypic and epigenetic changes in response to heat stress in Arabidopsis thaliana. Plant Signal. Behav. 9:e27971. doi: 10.4161/psb.27971

Min, L., Li, Y., Hu, Q., Zhu, L., Gao, W., Wu, Y., et al. (2014). Sugar and auxin signaling pathways respond to high-temperature stress during anther development as revealed by transcript profiling analysis in cotton. Plant Physiol. 164, 1293-1308. doi: 10.1104/pp.113.232314

Mittler, R., Finka, A., and Goloubinoff, P. (2012). How do plants feel the heat? Trends Biochem. Sci. 37, 118-125. doi: 10.1016/j.tibs.2011.11.007

Moglia, A., Gianoglio, S., Acquadro, A., Valentino, D., Milani, A. M., Lanteri, S., et al. (2019). Identification of DNA methyltransferases and demethylases in Solanum melongena L., and their transcription dynamics during fruit development and after salt and drought stresses. PLoS One 14:e0223581. doi: 10.1371/journal.pone.0223581

Molinier, J., Ries, G., Zipfel, C., and Hohn, B. (2006). Transgeneration memory of stress in plants. Nature 442, 1046-1049. doi: 10.1038/nature05022

Mousavi, S., Regni, L., Bocchini, M., Mariotti, R., Cultrera, N. G. M., Mancuso, S., et al. (2019). Physiological, epigenetic and genetic regulation in some olive cultivars under salt stress. Sci. Rep. 9:1093. doi: 10.1038/s41598-018-37496-5

Naydenov, M., Baev, V., Apostolova, E., Gospodinova, N., Sablok, G., Gozmanova, M., et al. (2015). High-temperature effect on genes engaged in DNA methylation and affected by DNA methylation in Arabidopsis. Plant Physiol. Biochem. 87, 102-108. doi: 10.1016/j.plaphy.2014.12.022

Negrão, S., Schmöckel, S. M., and Tester, M. (2017). Evaluating physiological responses of plants to salinity stress. Ann. Bot. 119, 1-11. doi: 10.1093/aob/ mcw191

Nuthikattu, S., Mccue, A. D., Panda, K., Fultz, D., Defraia, C., Thomas, E. N., et al. (2013). The initiation of epigenetic silencing of active transposable elements is triggered by RDR6 and 21-22 nucleotide small interfering RNAs. Plant Physiol. 162, 116-131. doi: 10.1104/pp.113.216481

Ou, X. F., Zhang, Y. H., Xu, C. M., Lin, X. Y., Zang, Q., Zhuang, T. T., et al. (2012). Transgenerational inheritance of modified DNA methylation patterns and enhanced tolerance induced by heavy metal stress in rice (Oryza sativa L.). PLoS One 7:e41143. doi: 10.1371/journal.pone.0041143

Papa, C. M., Springer, N. M., Muszynski, M. G., Meeley, R., and Kaeppler, S. M. (2001). Maize chromomethylase Zea methyltransferase 2 is required for CpNpG methylation. Plant Cell 13, 1919-1928. doi: 10.1105/tpc.010064 
Park, J. S., Frost, J. M., Park, K., Ohr, H., Park, G. T., Kim, S., et al. (2017). Control of DEMETER DNA demethylase gene transcription in male and female gamete companion cells in Arabidopsis thaliana. Proc. Natl. Acad. Sci. U.S.A. 114, 2078-2083. doi: 10.1073/pnas.1620592114

Pecinka, A., Dinh, H. Q., Baubec, T., Rosa, M., Lettner, N., and Mittelsten Scheid, O. (2010). Epigenetic regulation of repetitive elements is attenuated by prolonged heat stress in Arabidopsis. Plant Cell 22, 3118-3129. doi: 10.1105/tpc. 110.078493

Peng, Y., Zhang, Y., Gui, Y., An, D., Liu, J., Xu, X., et al. (2019). Elimination of a retrotransposon for quenching genome instability in modern rice. Mol. Plant 12, 1395-1407. doi: 10.1016/j.molp.2019.06.004

Pontier, D., Picart, C., Roudier, F., Garcia, D., Lahmy, S., Azevedo, J., et al. (2012). NERD, a plant-specific GW protein, defines an additional RNAi-dependent chromatin-based pathway in Arabidopsis. Mol. Cell. 48, 121-132. doi: 10.1016/ j.molcel.2012.07.027

Popova, O. V., Dinh, H. Q., Aufsatz, W., and Jonak, C. (2013). The RdDM pathway is required for basal heat tolerance in Arabidopsis. Mol. Plant 6, 396-410. doi: $10.1093 / \mathrm{mp} / \mathrm{sst} 023$

Preite, V., Oplaat, C., Biere, A., Kirschner, J., Van Der Putten, W. H., and Verhoeven, K. J. F. (2018). Increased transgenerational epigenetic variation, but not predictable epigenetic variants, after environmental exposure in two apomictic dandelion lineages. Ecol. Evol. 8, 3047-3059. doi: 10.1002/ece3. 3871

Quadrana, L., and Colot, V. (2016). Plant transgenerational epigenetics. Annu. Rev. Genet. 50, 467-491. doi: 10.1146/annurev-genet-120215-035254

Rasmann, S., De Vos, M., Casteel, C. L., Tian, D., Halitschke, R., Sun, J. Y., et al. (2012). Herbivory in the previous generation primes plants for enhanced insect resistance. Plant Physiol. 158, 854-863. doi: 10.1104/pp.111.187831

Reinders, J., Wulff, B. B., Mirouze, M., Marí-Ordóñez, A., Dapp, M., Rozhon, W., et al. (2009). Compromised stability of DNA methylation and transposon immobilization in mosaic Arabidopsis epigenomes. Genes Dev. 23, 939-950. doi: 10.1101/gad.524609

Rutowicz, K., Puzio, M., Halibart-Puzio, J., Lirski, M., Kotliński, M., Kroteń, M. A., et al. (2015). A specialized histone $\mathrm{H} 1$ variant is required for adaptive responses to complex abiotic stress and related DNA methylation in Arabidopsis. Plant Physiol. 169, 2080-2101. doi: 10.1104/pp.15.00493

Saidi, Y., Finka, A., Muriset, M., Bromberg, Z., Weiss, Y. G., Maathuis, F. J., et al. (2009). The heat shock response in moss plants is regulated by specific calciumpermeable channels in the plasma membrane. Plant Cell 21, 2829-2843. doi: $10.1105 /$ tpc. 108.065318

Sanchez, D. H., and Paszkowski, J. (2014). Heat-induced release of epigenetic silencing reveals the concealed role of an imprinted plant gene. PLoS Genet. 10:e1004806. doi: 10.1371/journal.pgen.1004806

Saze, H., Mittelsten Scheid, O., and Paszkowski, J. (2003). Maintenance of CpG methylation is essential for epigenetic inheritance during plant gametogenesis. Nat. Genet. 34, 65-69. doi: 10.1038/ng1138

Scoville, A. G., Barnett, L. L., Bodbyl-Roels, S., Kelly, J. K., and Hileman, L. C. (2011). Differential regulation of a MYB transcription factor is correlated with transgenerational epigenetic inheritance of trichome density in Mimulus guttatus. New Phytol. 191, 251-263. doi: 10.1111/j.1469-8137.2011. 03656.x

Shen, X., De Jonge, J., Forsberg, S. K., Pettersson, M. E., Sheng, Z., Hennig, L., et al. (2014). Natural CMT2 variation is associated with genome-wide methylation changes and temperature seasonality. PLoS Genet. 10:e1004842. doi: 10.1371/ journal.pgen.1004842

Singh, J., Mishra, V., Wang, F., Huang, H. Y., and Pikaard, C. S. (2019). Reaction mechanisms of Pol IV, RDR2, and DCL3 drive RNA channeling in the siRNAdirected DNA methylation pathway. Mol. Cell. 75, 576.e-589.e. doi: 10.1016/j. molcel.2019.07.008

Skvortsova, K., Iovino, N., and Bogdanović, O. (2018). Functions and mechanisms of epigenetic inheritance in animals. Nat. Rev. Mol. Cell Biol. 19, 774-790. doi: 10.1038/s41580-018-0074-2

Slaughter, A., Daniel, X., Flors, V., Luna, E., Hohn, B., and Mauch-Mani, B. (2012). Descendants of primed Arabidopsis plants exhibit resistance to biotic stress. Plant Physiol. 158, 835-843. doi: 10.1104/pp.111.191593

Slotkin, R. K., Freeling, M., and Lisch, D. (2005). Heritable transposon silencing initiated by a naturally occurring transposon inverted duplication. Nat. Genet. 37, 641-644. doi: 10.1038/ng1576
Smith, Z. D., Chan, M. M., Mikkelsen, T. S., Gu, H., Gnirke, A., Regev, A., et al. (2012). A unique regulatory phase of DNA methylation in the early mammalian embryo. Nature 484, 339-344. doi: 10.1038/nature10960

Song, Y., Ci, D., Tian, M., and Zhang, D. (2016). Stable methylation of a non-coding RNA gene regulates gene expression in response to abiotic stress in Populus simonii. J. Exp. Bot. 67, 1477-1492. doi: 10.1093/jxb/erv543

Stroud, H., Do, T., Du, J., Zhong, X., Feng, S., Johnson, L., et al. (2014). Non-CG methylation patterns shape the epigenetic landscape in Arabidopsis. Nat. Struct. Mol. Biol. 21, 64-72. doi: 10.1038/nsmb.2735

Sultan, S. E., Barton, K., and Wilczek, A. M. (2009). Contrasting patterns of transgenerational plasticity in ecologically distinct congeners. Ecology 90, 18311839. doi: 10.1890/08-1064.1

Tan, F., Lu, Y., Jiang, W., Wu, T., Zhang, R., Zhao, Y., et al. (2018). DDM1 represses noncoding RNA expression and RNA-directed DNA methylation in heterochromatin. Plant Physiol. 177, 1187-1197. doi: 10.1104/pp.18.00352

Tan, M. P. (2010). Analysis of DNA methylation of maize in response to osmotic and salt stress based on methylation-sensitive amplified polymorphism. Plant Physiol. Biochem. 48, 21-26. doi: 10.1016/j.plaphy.2009.10.005

Tang, X., Wang, Q., Yuan, H., and Huang, X. (2018). Chilling-induced DNA demethylation is associated with the cold tolerance of Hevea brasiliensis. BMC Plant Biol. 18:70. doi: 10.1186/s12870-018-1276-7

Tao, Z., Shen, L., Gu, X., Wang, Y., Yu, H., and He, Y. (2017). Embryonic epigenetic reprogramming by a pioneer transcription factor in plants. Nature 551, 124-128. doi: 10.1038/nature24300

Teixeira, F. K., Heredia, F., Sarazin, A., Roudier, F., Boccara, M., Ciaudo, C., et al. (2009). A role for RNAi in the selective correction of DNA methylation defects. Science 323, 1600-1604. doi: 10.1126/science.1165313

Tittel-Elmer, M., Bucher, E., Broger, L., Mathieu, O., Paszkowski, J., and Vaillant, I. (2010). Stress-induced activation of heterochromatic transcription. PLoS Genet. 6:e1001175. doi: 10.1371/journal.pgen.1001175

Trap-Gentil, M. V., Hébrard, C., Lafon-Placette, C., Delaunay, A., Hagège, D., Joseph, C., et al. (2011). Time course and amplitude of DNA methylation in the shoot apical meristem are critical points for bolting induction in sugar beet and bolting tolerance between genotypes. J. Exp. Bot. 62, 2585-2597. doi: $10.1093 /$ jxb/erq433

Van Dooren, T. J. M., Silveira, A. B., Gilbault, E., Jiménez-Gómez, J. M., Martin, A., Bach, L., et al. (2020). Mild drought in the vegetative stage induces phenotypic, gene expression and DNA methylation plasticity in Arabidopsis but no transgenerational effects. J. Exp. Bot. 71, 3588-3602. doi: 10.1093/jxb/ eraal32

Verhoeven, K. J., Jansen, J. J., Van Dijk, P. J., and Biere, A. (2010). Stress-induced DNA methylation changes and their heritability in asexual dandelions. New Phytol. 185, 1108-1118. doi: 10.1111/j.1469-8137.2009.03121.x

Virdi, K. S., Laurie, J. D., Xu, Y. Z., Yu, J., Shao, M. R., Sanchez, R., et al. (2015). Arabidopsis MSH1 mutation alters the epigenome and produces heritable changes in plant growth. Nat. Commun. 6:6386. doi: 10.1038/ncomms7386

Virdi, K. S., Wamboldt, Y., Kundariya, H., Laurie, J. D., Keren, I., Kumar, K. R. S., et al. (2016). MSH1 is a plant organellar DNA binding and thylakoid protein under precise spatial regulation to alter development. Mol. Plant 9, 245-260. doi: 10.1016/j.molp.2015.10.011

Wang, M., Qin, L., Xie, C., Li, W., Yuan, J., Kong, L., et al. (2014). Induced and constitutive DNA methylation in a salinity-tolerant wheat introgression line. Plant Cell Physiol. 55, 1354-1365. doi: 10.1093/pcp/pcu059

Wang, W., Huang, F., Qin, Q., Zhao, X., Li, Z., and Fu, B. (2015). Comparative analysis of DNA methylation changes in two rice genotypes under salt stress and subsequent recovery. Biochem. Biophys. Res. Commun. 465, 790-796. doi: 10.1016/j.bbrc.2015.08.089

Wang, W., Qin, Q., Sun, F., Wang, Y., Xu, D., Li, Z., et al. (2016). Genome-wide differences in DNA methylation changes in two contrasting rice genotypes in response to drought conditions. Front. Plant Sci. 7:1675. doi: 10.3389/fpls.2016. 01675

Wang, W. S., Pan, Y. J., Zhao, X. Q., Dwivedi, D., Zhu, L. H., Ali, J., et al. (2011). Drought-induced site-specific DNA methylation and its association with drought tolerance in rice (Oryza sativa L.). J. Exp. Bot. 62, 1951-1960. doi: $10.1093 /$ jxb/erq391

Wassenegger, M., Heimes, S., Riedel, L., and Sänger, H. L. (1994). RNA-directed de novo methylation of genomic sequences in plants. Cell 76, 567-576. doi: 10.1016/0092-8674(94)90119-8 
Whittle, C. A., Otto, S. P., Johnston, M. O., and Krochko, J. E. (2009). Adaptive epigenetic memory of ancestral temperature regime in Arabidopsis thaliana. Botany 87, 650-657. doi: 10.1139/b09-030

Wibowo, A., Becker, C., Marconi, G., Durr, J., Price, J., Hagmann, J., et al. (2016). Hyperosmotic stress memory in Arabidopsis is mediated by distinct epigenetically labile sites in the genome and is restricted in the male germline by DNA glycosylase activity. eLife 5:e13546. doi: 10.7554/eLife.13546

Williams, B. P., Pignatta, D., Henikoff, S., and Gehring, M. (2015). Methylationsensitive expression of a DNA demethylase gene serves as an epigenetic rheostat. PLoS Genet. 11:e1005142. doi: 10.1371/journal.pgen.1005142

Woo, H. R., Dittmer, T. A., and Richards, E. J. (2008). Three SRAdomain methylcytosine-binding proteins cooperate to maintain global $\mathrm{CpG}$ methylation and epigenetic silencing in Arabidopsis. PLoS Genet. 4:e1000156. doi: 10.1371/journal.pgen.1000156

Wu, L., Mao, L., and Qi, Y. (2012). Roles of dicer-like and argonaute proteins in TAS-derived small interfering RNA-triggered DNA methylation. Plant Physiol. 160, 990-999. doi: 10.1104/pp.112.200279

Wu, L., Zhou, H., Zhang, Q., Zhang, J., Ni, F., Liu, C., et al. (2010). DNA methylation mediated by a microRNA pathway. Mol. Cell 38, 465-475. doi: 10.1016/j.molcel.2010.03.008

Xiao, C.-L., Zhu, S., He, M., Chen, D., Zhang, Q., Chen, Y., et al. (2018). $N^{6}$-methyladenine DNA modification in the human genome. Mol. Cell 71, 306.e3-318.e3. doi: 10.1016/j.molcel.2018.06.015

Xie, H., Sun, Y., Cheng, B., Xue, S., Cheng, D., Liu, L., et al. (2019). Variation in ICE1 methylation primarily determines phenotypic variation in freezing tolerance in Arabidopsis thaliana. Plant Cell Physiol. 60, 152-165. doi: 10.1093/ pcp/pcy197

Xie, H. J., Li, H., Liu, D., Dai, W. M., He, J. Y., Lin, S., et al. (2015). ICE1 demethylation drives the range expansion of a plant invader through cold tolerance divergence. Mol. Ecol. 24, 835-850. doi: 10.1111/mec.13067

Xu, J., Zhou, S., Gong, X., Song, Y., Van Nocker, S., Ma, F., et al. (2018). Single-base methylome analysis reveals dynamic epigenomic differences associated with water deficit in apple. Plant Biotechnol. J. 16, 672-687. doi: 10.1111/pbi.12820

Xu, R., Wang, Y., Zheng, H., Lu, W., Wu, C., Huang, J., et al. (2015). Salt-induced transcription factor MYB74 is regulated by the RNA-directed DNA methylation pathway in Arabidopsis. J. Exp. Bot. 66, 5997-6008. doi: 10.1093/jxb/erv312

Yang, D. L., Zhang, G., Tang, K., Li, J., Yang, L., Huang, H., et al. (2015). Dicerindependent RNA-directed DNA methylation in Arabidopsis. Cell Res. 26:1264. doi: $10.1038 /$ cr.2015.145

Yang, X., Sanchez, R., Kundariya, H., Maher, T., Dopp, I., Schwegel, R., et al. (2020). Segregation of an MSH1 RNAi transgene produces heritable nongenetic memory in association with methylome reprogramming. Nat. Commun. 11:2214. doi: 10.1038/s41467-020-16036-8

Yao, Y., Bilichak, A., Golubov, A., and Kovalchuk, I. (2012). ddm1 plants are sensitive to methyl methane sulfonate and $\mathrm{NaCl}$ stresses and are deficient in DNA repair. Plant Cell Rep. 31, 1549-1561. doi: 10.1007/s00299-012-1269-1

Ye, R., Chen, Z., Lian, B., Rowley, M. J., Xia, N., Chai, J., et al. (2015). A dicerindependent route for biogenesis of siRNAs that direct DNA methylation in Arabidopsis. Mol. Cell. 61, 222-235. doi: 10.1016/j.molcel.2015.11.015

Ye, R., Wang, W., Iki, T., Liu, C., Wu, Y., Ishikawa, M., et al. (2012). Cytoplasmic assembly and selective nuclear import of Arabidopsis Argonaute4/siRNA complexes. Mol. Cell. 46, 859-870. doi: 10.1016/j.molcel.2012.04.013

Yuan, F., Yang, H., Xue, Y., Kong, D., Ye, R., Li, C., et al. (2014). OSCA1 mediates osmotic-stress-evoked $\mathrm{Ca}^{2+}$ increases vital for osmosensing in Arabidopsis. Nature 514, 367-371. doi: 10.1038/nature13593

Zemach, A., Kim, M. Y., Hsieh, P. H., Coleman-Derr, D., Eshed-Williams, L., Thao, K., et al. (2013). The Arabidopsis nucleosome remodeler DDM1 allows DNA methyltransferases to access H1-containing heterochromatin. Cell 153, 193-205. doi: 10.1016/j.cell.2013.02.033

Zhai, J., Bischof, S., Wang, H., Feng, S., Lee, T. F., Teng, C., et al. (2015). A one precursor one siRNA model for Pol IV-dependent siRNA biogenesis. Cell 163, 445-455. doi: 10.1016/j.cell.2015.09.032
Zhang, D., Guo, X., Xu, Y., Li, H., Ma, L., Yao, X., et al. (2019). OsCIPK7 pointmutation leads to conformation and kinase-activity change for sensing cold response. J. Integr. Plant Biol. 61, 1194-1200. doi: 10.1111/jipb.12800

Zhang, H., Lang, Z., and Zhu, J. K. (2018). Dynamics and function of DNA methylation in plants. Nat. Rev. Mol. Cell Biol. 19, 489-506. doi: 10.1038/ s41580-018-0016-Z

Zhang, Q., Liang, Z., Cui, X., Ji, C., Li, Y., Zhang, P., et al. (2018). $N^{6}$-methyladenine DNA methylation in Japonica and Indica rice genomes and its association with gene expression, plant development, and stress responses. Mol. Plant 11, 1492-1508. doi: 10.1016/j.molp.2018.11.005

Zhang, H., and Zhu, J. K. (2012). Active DNA demethylation in plants and animals. Cold. Spring Harb. Symp. Quant. Biol. 77, 161-173. doi: 10.1101/sqb.2012.77. 014936

Zhang, M., Yang, S., Nelakanti, R., Zhao, W., Liu, G., Li, Z., et al. (2020). Mammalian ALKBH1 serves as an $N^{6}$-mA demethylase of unpairing DNA. Cell Res. 30, 197-210. doi: 10.1038/s41422-019-0237-5

Zhang, W., Wang, N., Yang, J., Guo, H., Liu, Z., Zheng, X., et al. (2020). The saltinduced transcription factor GmMYB84 confers salinity tolerance in soybean. Plant Sci. 291, 110326. doi: 10.1016/j.plantsci.2019.110326

Zhang, X., Yazaki, J., Sundaresan, A., Cokus, S., Chan, S. W., Chen, H., et al. (2006). Genome-wide high-resolution mapping and functional analysis of DNA methylation in Arabidopsis. Cell 126, 1189-1201. doi: 10.1016/j.cell.2006. 08.003

Zhang, Y. Y., Fischer, M., Colot, V., and Bossdorf, O. (2013). Epigenetic variation creates potential for evolution of plant phenotypic plasticity. New Phytol. 197, 314-322. doi: 10.1111/nph.12010

Zheng, X., Chen, L., Li, M., Lou, Q., Xia, H., Wang, P., et al. (2013). Transgenerational variations in DNA methylation induced by drought stress in two rice varieties with distinguished difference to drought resistance. PLoS One 8:e80253. doi: 10.1371/journal.pone.0080253

Zheng, X., Chen, L., Xia, H., Wei, H., Lou, Q., Li, M., et al. (2017). Transgenerational epimutations induced by multi-generation drought imposition mediate rice plant's adaptation to drought condition. Sci. Rep. 7:39843. doi: $10.1038 /$ srep 39843

Zhong, S. H., Liu, J. Z., Jin, H., Lin, L., Li, Q., Chen, Y., et al. (2013). Warm temperatures induce transgenerational epigenetic release of RNA silencing by inhibiting siRNA biogenesis in Arabidopsis. Proc. Natl. Acad. Sci. U.S.A. 110, 9171-9176. doi: 10.1073/pnas.1219655110

Zhou, C., Wang, C., Liu, H., Zhou, Q., Liu, Q., Guo, Y., et al. (2018). Identification and analysis of adenine $N^{6}$-methylation sites in the rice genome. Nat. Plants 4 , 554-563. doi: 10.1038/s41477-018-0214-x

Zhu, J. K. (2016). Abiotic stress signaling and responses in plants. Cell 167, 313-324. doi: 10.1016/j.cell.2016.08.029

Zhu, N., Cheng, S., Liu, X., Du, H., Dai, M., Zhou, D. X., et al. (2015). The R2R3type MYB gene OsMYB91 has a function in coordinating plant growth and salt stress tolerance in rice. Plant Sci. 236, 146-156. doi: 10.1016/j.plantsci.2015. 03.023

Zilberman, D., Gehring, M., Tran, R. K., Ballinger, T., and Henikoff, S. (2007). Genome-wide analysis of Arabidopsis thaliana DNA methylation uncovers an interdependence between methylation and transcription. Nat. Genet. 39, 61-69. doi: $10.1038 /$ ng1929

Conflict of Interest: The authors declare that the research was conducted in the absence of any commercial or financial relationships that could be construed as a potential conflict of interest.

Copyright $\odot 2020 \mathrm{Liu}$ and He. This is an open-access article distributed under the terms of the Creative Commons Attribution License (CC BY). The use, distribution or reproduction in other forums is permitted, provided the original author(s) and the copyright owner(s) are credited and that the original publication in this journal is cited, in accordance with accepted academic practice. No use, distribution or reproduction is permitted which does not comply with these terms. 